\title{
Energy and seismic drawbacks of masonry: a unified retrofitting solution
}

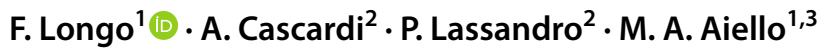

Received: 20 July 2021 / Revised: 3 August 2021 / Accepted: 4 August 2021 / Published online: 16 September 2021

(c) The Author(s) 2021

\begin{abstract}
All over the world, a large part of existing buildings is not adequate to satisfy the safety requirement and the thermal comfort criteria. For this reason, the interest in structural and energy retrofitting systems has steadily grown in the last decades. In this scenario, an innovative thermal resistant geopolymer mortar has been developed and used for Inorganic Matrix Composite (IMC) systems aimed to a combined seismic and energy new retrofitting technique. The geopolymer-based IMC is able to ensure competitive mechanical properties with respect to the traditional lime-based IMCs and, at the same time, a significant reduction in thermal conductivity. In this paper, an experimental program is reported considering small-scaled masonry panels with double-side IMC-retrofitting and determining both the in-plane shear strength and the thermal resistance. The experimental shear tests are aimed to compare the mechanical performance of the geopolymer innovative systems with those of the traditional lime-based ones. Moreover, the thermal resistance gain of the innovative solutions was measured and compared with traditional systems. The results evidenced the effectiveness of the proposed technique that significantly improved the performances of masonry walls from both the thermal and the mechanical point of view.
\end{abstract}

Keywords Geopolymer mortar · Seismic retrofitting · Energy improvement $\cdot$ Inorganic-mortar-composite $\cdot$ Fiber reinforced cementitious mortar $\cdot$ Masonry shear test

\section{Introduction}

Nowadays, a large portion of the building heritage daily manifests issues related to poor seismic performance (Fig. 1a) and thermal deficiencies (Fig. 1b). It is estimated that, in the European Union, the annual cost of repair and

\section{F. Longo}

fabio.longo@unisalento.it

A. Cascardi

alessio.cascardi@itc.cnr.it

P. Lassandro

paola.lassandro@itc.cnr.it

M. A. Aiello

antonietta.aiello@unisalento.it

1 Department of Engineering for Innovation, University of Salento, 73100 Lecce, Italy

2 Construction Technologies Institute, National Research Council, ITC-CNR, 70124 Bari, Italy

3 Construction Technologies Institute, National Research Council, ITC-CNR, San Giuliano Milanese, 20098 Milan, Italy maintenance of existing buildings represents about the 50\% of the total construction budget [1]. For this reason, novel approaches to optimize the repair and renovation of the built heritage are highly sought by researchers, practitioners and policy makers. In addition, it was recognized in the existing building sector the biggest potential for savings in terms of both energy consumption and $\mathrm{CO}_{2}$ emissions [2].

As proved by the conspicuous literature and the considerable interest of practitioners, Fiber-Reinforced Polymer (FRP) represents a well-known material involved in structural retrofitting. FRP-based systems have been widely experienced in civil engineering for strengthening applications, as reported in Refs. [3, 4]. Nowadays, undisputed advantages are recognized in FRP application, as lightweight, high elastic modulus, high strength-to-weight ratio and corrosion resistance. Nonetheless, the use of organic mortar for bonding leads to some acknowledged disadvantages, as susceptibility to high temperature or humidity, brittle failure mode and inhibition of the breathability of the substrate.

A new composite-based system was assessed in order to overcome FRP's drawbacks, namely the Inorganic Matrix Composite (IMC). Typically, the IMC is made of two 


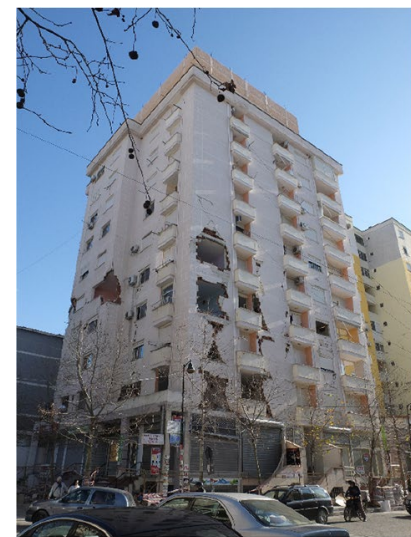

(a)

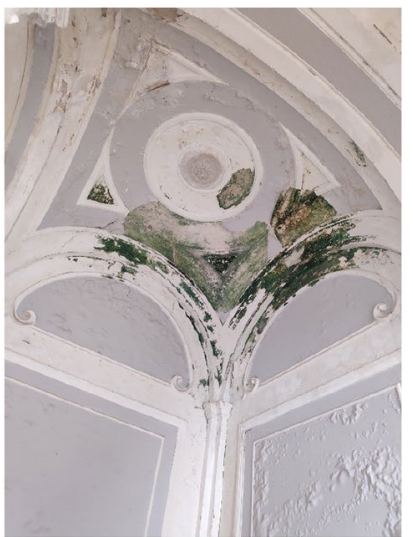

(b)
Fig. 1 Examples of a seismic damages (Durres in Albania, earthquake 2019) and b thermal deficiencies (Bari in Italy, historic building 2020)

components: a fabric and a matrix. The former is an open grid which provides resistance, the latter is an organic mortar which bonds the fabric to the substrate of the reinforced element. The achievement is a less resistant composite with respect to the traditional FRP (due to the lower fiber content per unit of matrix volume), but more porous (due to the voids in the inorganic matrix) and so able to guarantee the original breathability of the existing substrate. For this reason, the IMC was intended to be adopted in masonry structural rehabilitation and upgrade [5-8].

A largely experienced application of the IMC-system is related to the reinforcement of in-plane masonry walls. In case the reinforcement within the inorganic matrix is almost dry, the IMC is also called Fabric Reinforced Cementitious Mortar (FRCM) [9]; while the term Composite Reinforced Mortar (CRM) refers to FRP grid in a mortar layer thicker than $3 \mathrm{~cm}$ per side, according to Ref. [10]. In this field, the scientific papers adopted further nomenclature, as Textile Reinforced Mortar (TRM) [9], Cementitious Matrix Grid (CMG) [11], Inorganic Matrix Grid (IMG) [12].

The available literature concerning masonry walls retrofitted with IMCs is now relatively conspicuous [12-56]. Nevertheless, the potential use of a combined system for mechanical and energy improvements in existing buildings is rarely considered within the experimental programs. Inorganic matrix is essentially a plaster for existing building; thus, it can be insulating oriented when a significant thickness associated to a sufficiently low thermal conductivity mortar is provided. In recent years, some researchers tried to assess an integrated system for seismic and energy retrofitting by combining IMC with insulation materials. The proposed systems were based on the use of a low-thermal conductivity mortar [28], or the incorporation of an insulating layer $[57,58]$. In the first case, the low compressive strength of the mortar highlighted a lower gain in strengthening compared to traditional matrices. In the second case, the use of different layers led to a large thickness of the resulting system and to the necessity to ensure that thermal bridges and interstitial condensation are avoided.

Therefore, the contribution of IMC-matrix for mechanical and thermal purposes is an open issue since few researchers focused on this topic, mostly referring to the performances of reinforced masonry wall.

In Refs. [59, 60] a novel geopolymer-based mortar was assessed in order to be adopted as IMC-matrix. The possibility of partially replace cement materials and use, for example, geopolymer binders in concrete and mortar is well-known and widely experienced in literature [61-66]. Due to the high-strength of geopolymer binders, the aggregate was fully substituted with expanded glass aggregate. The lightweight aggregate, involved instead of sand, contributed to reduce density and thermal conductivity of the proposed matrix. The mortar was finally compared with a traditional lime-based one, exhibiting similar mechanical properties and approximately two-fold reduction in thermal conductivity.

From a mechanical point of view, further investigations are required to better understand the role of the fragile matrix and the interface behavior (mortar-substrate and mortar-mesh). In fact, in case of FRP-like material, the polymeric matrix generally shows high mechanical properties with respect to the substrate while the chemical adhesion leads to a uniform distribution of the strain within the internal reinforcement; contrarily, for the FRCMs, the mortar properties could be comparable to those of the substrate and the chemical adhesion between the fibers and the matrix is lower. Thus, after a certain level of tensile stress, the matrix exhibits cracking and the fabric tends to slip within the mortar in a not-uniform way, as discussed in Refs. [67]. In addition, when an inorganic binder is considered the impregnation of fibers within the single yarn appears also not uniform, since the poor capacity of the matrix to penetrate within the yarn. Therefore, only the external fibers are in contact with the mortar, and the yarn failure occurs by a combination of fibers sliding and rupture.

Based on the encouraging outcomes of the innovative systems presented in Refs. [59, 60] and considering the necessity to further investigate the role of the inorganic matrix in the structural response of strengthened elements, an experimental investigation was carried out on reinforced fired clay brick masonry panels under in-plane shear. The goals are to compare the performances of traditional IMCs (lime-based matrix) with respect to the innovative ones and to provide more insights about the effect of the inorganic matrix in the shear strength gain. 


\section{Experimental program}

The experimental campaign layout is summarized in Table 1. In particular, the label of the specimen, the type of masonry and the used strengthening systems are detailed. The following series were involved:

- URM refers to Un-Reinforced Masonry walls, namely the control specimens;

- NHL refers to masonry panels strengthened by $3-\mathrm{cm}$ thick Natural Hydraulic Lime (NHL) mortar layer per side;
- GPM refers to masonry panels strengthened by $3-\mathrm{cm}$ thick GeoPolymer Mortar (GPM) per side;

- $\quad$ FRCM refers to masonry panels strengthened by a FRCM system made with a dry AR glass $12 \times 12 \mathrm{~mm}^{2}$ fiber mesh and a $15 \mathrm{~mm}$ layer of NHL mortar;

- FRGM refers to masonry panels strengthened by a dry AR glass $12 \times 12 \mathrm{~mm}^{2}$ fiber mesh in a $15 \mathrm{~mm}$ layer of GPM;

- CRM refers to masonry panels strengthened by a glass FRP mesh in a $30 \mathrm{~mm}$ layer of NHL mortar;

- CRGM refers to masonry panels strengthened by a glass FRP mesh in a $30 \mathrm{~mm}$ layer of GPM;
Table 1 Experimental campaign layout $(*=$ unidirectional $)$

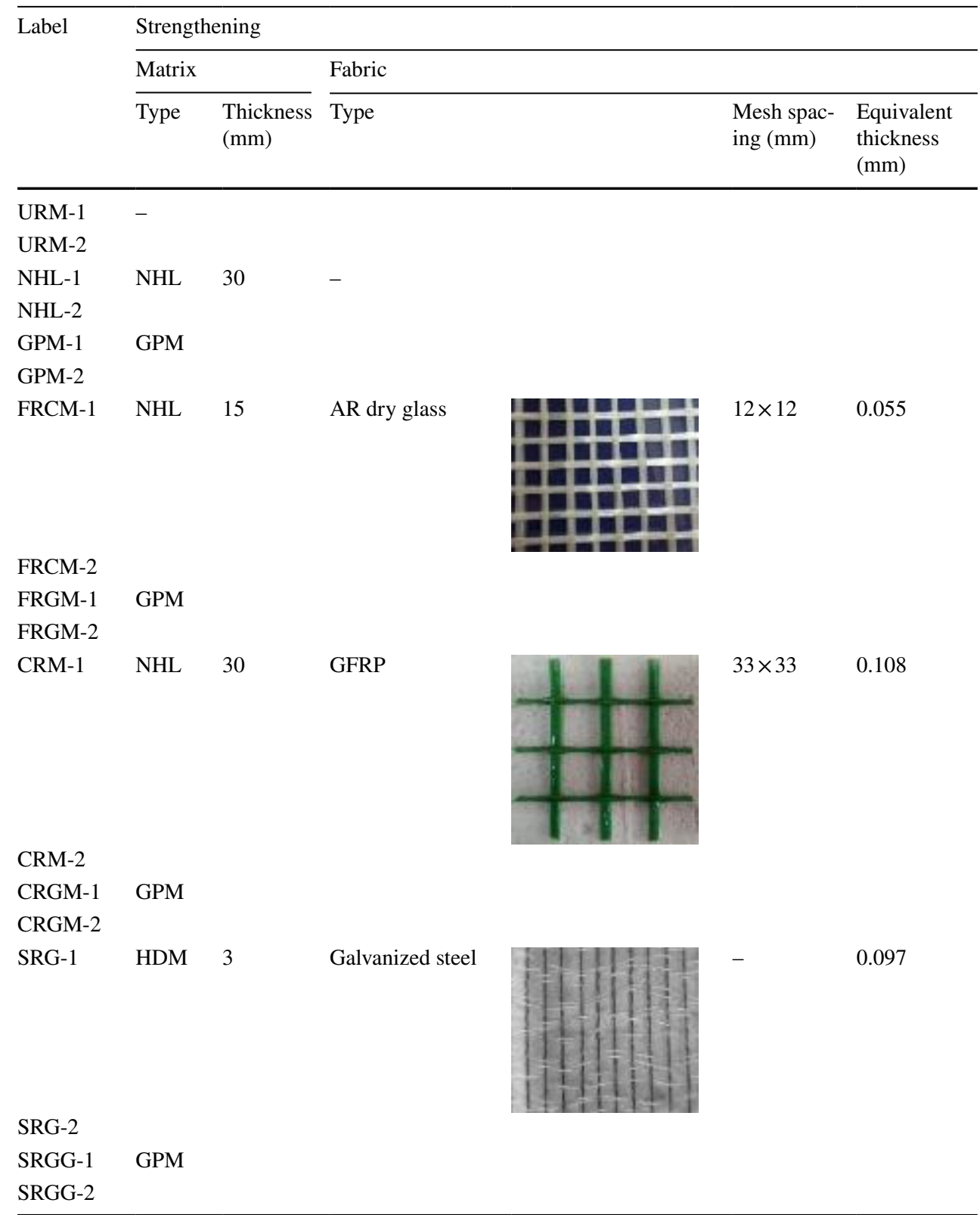


Fig. 2 Experimental test of: a clay brick, $\mathbf{b}$ mortar (compression), $\mathbf{c}$ mortar (flexural) and $\mathbf{d}$ masonry

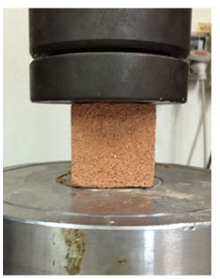

(a)

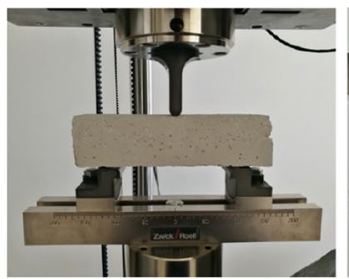

(b)

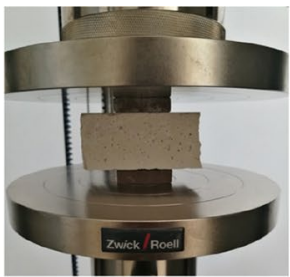

(c)

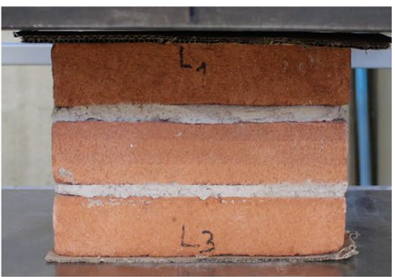

(d)
- $\underline{\text { SRG }}$ refers to masonry panels strengthened by Steel Reinforced Grout, a high-strength steel fabric in a $3 \mathrm{~mm}$ layer of High Ductile Mortar (HDM);

- SRGG refers to masonry panels strengthened by Steel Reinforced Geopolymer Grout, a high-strength steel fabric in a $3 \mathrm{~mm}$ layer of GPM.

In every case, the strengthening was applied on both sides of the masonry panel without transversal connectors. Two specimens per series were manufactured according to the end-number in the label (e.g. URM-1 or URM-2). Thermal and mechanical tests were both performed on every system in order to determine shear strength, stiffness, ductility and thermal resistance. It should be underlined that the SRG and SRGG samples were not thermally tested, since the thickness of the matrix $(<10 \mathrm{~mm})$ used, on the basis of the supplier indications, is not sufficient to guarantee an appreciable thermal resistance variation, with respect to the URM sample. However, the mechanical performances of SRGG system has been investigated aiming to evaluate its possible application in case of static and thermal retrofitting once a thicker layer of matrix will be utilized.

\subsection{Materials and sample preparation}

Compression tests were performed on the clay brick (Fig. 2a), according to Ref. [68]. The joints' mortar was characterized by both flexural (Fig. 2b) and compressive test (Fig. 2c), as prescribed in Ref. [69]. Tests revealed an average brick compressive strength equal to $24.06 \mathrm{MPa}$, a mortar flexural strength of $3.25 \mathrm{MPa}$ and a mortar compressive strength of $8.88 \mathrm{MPa}$. A total of six masonry wallets, made of three bricks and two horizontal joints (Fig. 2d, according to Ref. [70]), were subjected to compression and the recorded average strength was $5.16 \mathrm{MPa}$.

The IMC-systems (FRCCM, FRGM, SRG, SRGG) were characterized according to Italian Standards for FRCM qualification [71]. For every system, 9 coupons of the dimensions prescribed in Ref. [71] were manufactured and labeled by adding IMC to the name of the masonry sample. In addition, all the fabrics involved in IMC-system were characterized by direct tensile test, involving 9 samples for each fabric type. The matrices were characterized according to
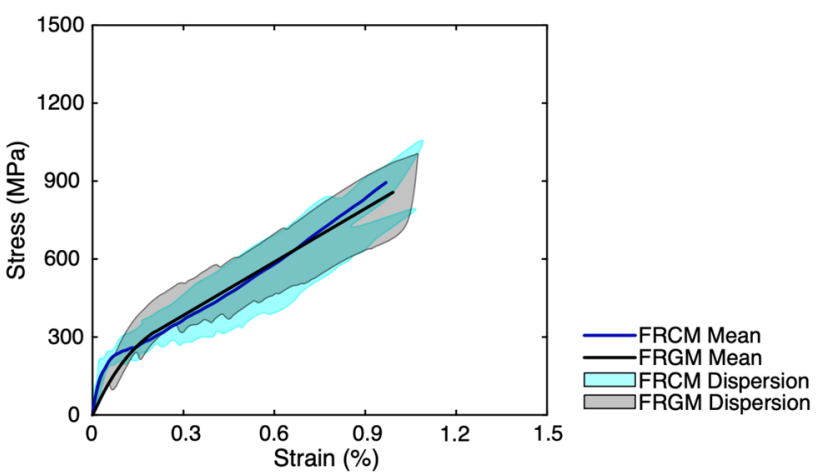

(a)

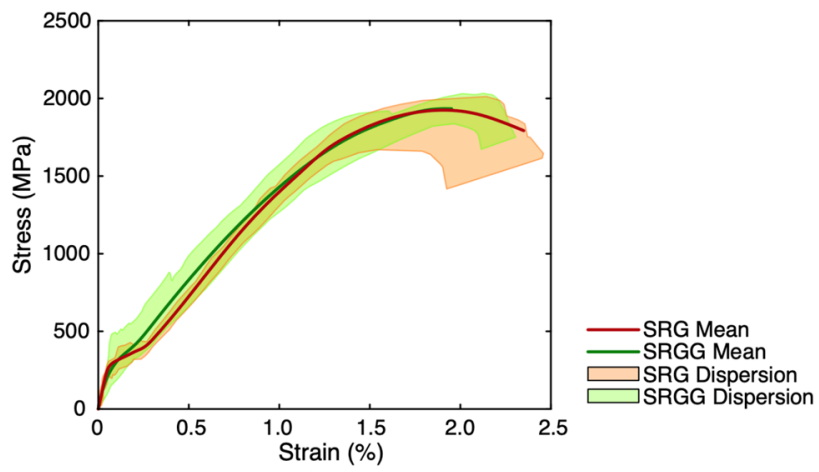

(b)

Fig. 3 Stress versus Strain curve of: a FRCM, FRGM and b SRG, SRGG with relative dispersion

Ref. [69]. The stress-strain relationships of the IMC-systems are reported in Fig. 3. In detail, the stress was evaluated dividing the applied load by the cross-section of the fabric, while the strain is measured referring to the utilized gauge length, equal to $10 \mathrm{~cm}$. From the curves, the linear slopes of the initial and final phases were determined. FRCM and FRGM specimens exhibited a quasi bi-linear behavior (Fig. 3a) and a fabric-rupture failure, generally occurring in the middle of the coupon (see Fig. 4a, c). While, SRG and SRGG specimens exhibited a quasi tri-linear behavior (Fig. 3b) and a fabric-rupture failure, generally occurring near the gripping (see Fig. 4b, d). The tensile strength of FRCM $(891 \pm 142 \mathrm{MPa})$ is much lower if compared with SRG $(1909 \pm 115 \mathrm{MPa})$. Similarly, SRG manifested a higher ultimate strain $(2.34 \pm 0.21 \%$ versus $0.87 \pm 0.17 \%)$. Even SRGG curve and properties were found comparable with the 


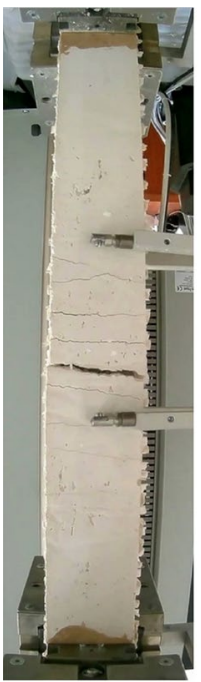

(a)

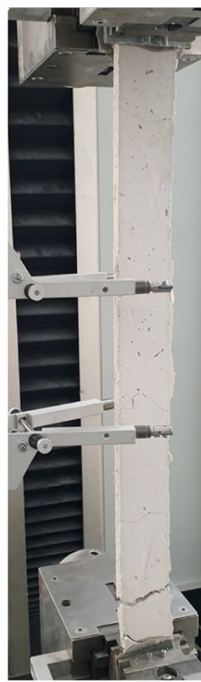

(b)

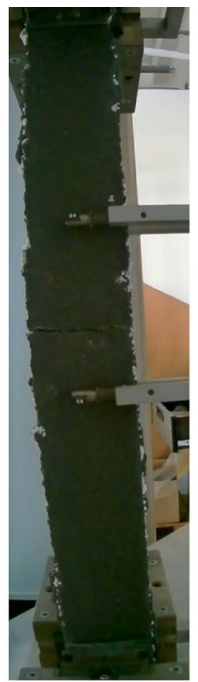

(c)

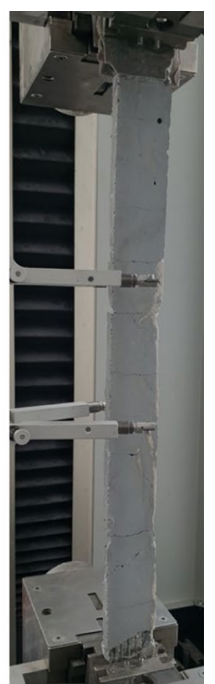

(d)
Fig. 4 IMC-systems cracking patterns: a FRCM, b SRG, c FRGM and d SRGG

ones of SRG, with a tensile strength and an ultimate strain equal to $1959 \pm 118 \mathrm{MPa}$ and $2.03 \pm 0.22 \%$, respectively. The steel fabric seems more exploited, since the tensile strength ratio between IMC systems and the corresponding fabrics was higher for SRG and SRGG (91.51\% and 93.91\%, respectively) with respect to FRCM and FRGM (45.71\% and $44.53 \%$, respectively). As concerns the CRM systems, the tensile properties of the GFRP grid have been evaluated involving 9 samples, according to Ref. [71].

The properties of the all the materials involved in the experimental campaign are listed in Table 2, where also the reference Standards are reported.

The experimental program involved $510 \mathrm{~mm} \times 510 \mathrm{~mm} \times 120 \mathrm{~mm}$ masonry panels, as shown in Fig. $5 \mathrm{a}$, made up of $250 \mathrm{~mm} \times 120 \mathrm{~mm} \times 55 \mathrm{~mm}$ clay bricks and lime-based mortar joints, $10 \mathrm{~mm}$ thick. In order to guarantee the uniform thickness of the mortar steel pins were utilized, as shown in Fig. 5b.

All the retrofitting systems were applied on the masonry substrate after the surface was cleaned and wetted in order to reduce the presence of dust and, at the same time, avoid the masonry's water absorption from the retrofitting-mortar. As reported in the following figures, the sample was arranged ensuring that the retrofitted surface was horizontal. In such way, the preparation of the samples was easier and faster.

The NHL and GPM samples were prepared by applying the mortar-layer $30 \mathrm{~mm}$ thick, In Fig. 6a the sketch of NHL and GPM are illustrated, while the preparation of NHL and GPM are illustrated in Fig. 6b and c, respectively.

The same mortars were later adopted respectively as matrices in FRCM and FRGM with a dry AR (Alkali Resistant) glass fiber mesh. The samples were manufactured as shown in Fig. 7. Firstly, half thickness of mortar was applied. After that, the fabric was placed and covered with the second layer of mortar. According to supplier recommendations, an adhesion promoter (IPN-01 type) was wet layout interposed between the matrix and the fabric, as shown in Fig. 8a, b, only in case of FRCM-system.

Similarly, the CRM and CRGM samples were prepared in two-steps per side in order to control fabric position, as illustrated in Fig. 9a. Even in this case, NHL and GPM were used as matrices, while a pre-impregnated GFRP mesh grid was incorporated in the systems.

Finally, the SRG and SRGG were assembled, as illustrated in Fig. 10a. For those samples, two pieces of fabric were needed to cover the wall side surface with an overlap length of about $10 \mathrm{~cm}$.

\subsection{Test methods}

The shear tests, in a diagonal compression configuration, were conducted by load control throughout a pump connected to a hydraulic jack. The whole test setup is illustrated in Fig. 11. Steel shoes were utilized for applying the load along the diagonal of the panel. The contact length between the steel shoe and the masonry panel edge was $100 \mathrm{~mm}$. A 30-ton load cell was adopted for the load recordings; while the specimens was equipped with two Linear Variables Displacements Transducers (LVDTs), located one per sides (A and B according to Fig. 11) and oriented in the vertical and the horizontal directions.

A $30 \mathrm{~mm}$ thick steel plate was placed at the bottom of the sample (under the steel shoe) in order to put-in-contrast the sample itself with the steel rigid frame and the hydraulic jack. The LVDTs were attached to the sample by means of epoxy-based putty and put in contact with a rigid steel bar (fixed to the masonry at the opposite extremity) in order to obtain a $500 \mathrm{~mm}$ measuring length. In addition, two cameras were located (one per side) in front of the sample for video recording the cracking pattern evolution and catch the dominant failure mode. The data acquisition was obtained by electronically connecting the load cell and the two LVDTs to a control panel with a computer for the elaboration.

The thermal performance of the specimens was evaluated by means of the experimental setup reported in Fig. 12 . A side of the wall (Hot side) was continuously heated by four $250 \mathrm{~W}$ halogen lamps to ensure steady state conditions (Fig. 12a), while the other side (Cold side) was kept without any thermal load (Fig. 12b). The halogen lamps were placed at the same positions for all the tests, according to the dimensions in Fig. 12c, d. Furthermore, a mono-dimensional heat flux was guaranteed by placing an insulating ring around each wall (Fig. 12b). All the samples were initially painted with the same color (white) in order to homogenize the reflectance of radiation from external surfaces [74]. 
Table 2 Properties of the materials involved in the experimental campaign

\begin{tabular}{|c|c|c|c|c|c|}
\hline Sub-system & Material & Property & Mean & $\operatorname{CoV}(\%)$ & Standard \\
\hline \multirow[t]{5}{*}{ Wall } & \multirow[t]{2}{*}{ Clay brick } & Compressive strength $^{\mathrm{a}}(\mathrm{MPa})$ & 24.06 & 14 & [68] \\
\hline & & Thermal conductivity ${ }^{\mathrm{b}}\left(\mathrm{W} \mathrm{m}^{-1} \mathrm{~K}^{-1}\right)$ & 0.565 & - & - \\
\hline & \multirow[t]{3}{*}{ Mortar joints } & Compressive strength (MPa) & 8.88 & 10 & [69] \\
\hline & & Flexural strength (MPa) & 3.25 & 7 & \\
\hline & & Thermal conductivity ${ }^{\mathrm{b}}\left(\mathrm{W} \mathrm{m}^{-1} \mathrm{~K}^{-1}\right)$ & 0.83 & - & - \\
\hline \multirow[t]{34}{*}{ Strengthening system } & \multirow[t]{3}{*}{ NHL-mortar } & Compressive strength (MPa) & 9.10 & 3 & [69] \\
\hline & & Flexural strength (MPa) & 3.10 & 7 & \\
\hline & & Thermal conductivity ${ }^{\mathrm{b}}\left(\mathrm{W} \mathrm{m}^{-1} \mathrm{~K}^{-1}\right)$ & 0.83 & - & - \\
\hline & \multirow[t]{3}{*}{ GPM-mortar } & Compressive strength (MPa) & 5.93 & 5 & [69] \\
\hline & & Flexural strength $(\mathrm{MPa})$ & 2.15 & 6 & \\
\hline & & Thermal conductivity $\left(\mathrm{W} \mathrm{m}^{-1} \mathrm{~K}^{-1}\right)$ & 0.234 & 2 & {$[72,73]$} \\
\hline & \multirow[t]{3}{*}{ HDM-mortar } & Compressive strength (MPa) & 15.60 & 10 & [69] \\
\hline & & Flexural strength (MPa) & 6.00 & 7 & \\
\hline & & Thermal conductivity ${ }^{\mathrm{b}}\left(\mathrm{W} \mathrm{m}^{-1} \mathrm{~K}^{-1}\right)$ & 0.75 & - & - \\
\hline & \multirow[t]{3}{*}{ AR glass fabric } & Tensile strength (MPa) & 1929 & 14 & [71] \\
\hline & & Young's modulus (GPa) & 108 & 16 & \\
\hline & & Ultimate strain $(\%)$ & 1.8 & 12 & \\
\hline & \multirow[t]{3}{*}{ GFRP Grid } & Tensile strength (MPa) & 1489 & 4 & [71] \\
\hline & & Young's modulus (GPa) & 48 & 6 & \\
\hline & & Ultimate strain (\%) & 3.1 & 7 & \\
\hline & \multirow[t]{3}{*}{ Steel } & Tensile strength (MPa) & 2086 & 3 & [71] \\
\hline & & Young's modulus (GPa) & 184 & 7 & \\
\hline & & Ultimate strain (\%) & 1.2 & 8 & \\
\hline & \multirow[t]{4}{*}{ FRCM-IMC } & Tensile strength (MPa) & 891 & 16 & [71] \\
\hline & & Ultimate strain (\%) & 0.87 & 19 & \\
\hline & & Un-cracked slope ${ }^{c}(\mathrm{GPa})$ & 514 & 8 & \\
\hline & & Cracked slope $^{c}(\mathrm{GPa})$ & 77 & 5 & \\
\hline & \multirow[t]{4}{*}{ FRGM-IMC } & Tensile strength (MPa) & 868 & 11 & [71] \\
\hline & & Ultimate strain (\%) & 0.87 & 19 & \\
\hline & & Un-cracked slope ${ }^{c}(\mathrm{GPa})$ & 229 & 10 & \\
\hline & & Cracked slope $^{c}(\mathrm{GPa})$ & 69 & 5 & \\
\hline & \multirow[t]{4}{*}{ SRG-IMC } & Tensile strength (MPa) & 1909 & 9 & [71] \\
\hline & & Ultimate strain (\%) & 2.34 & 9 & \\
\hline & & Un-cracked slope ${ }^{c}(\mathrm{GPa})$ & 445 & 11 & \\
\hline & & Cracked slope $^{\mathrm{c}}(\mathrm{GPa})$ & 136 & 7 & \\
\hline & \multirow[t]{4}{*}{ SRGG-IMC } & Tensile strength (MPa) & 1959 & 6 & [71] \\
\hline & & Ultimate strain (\%) & 2.03 & 11 & \\
\hline & & Un-cracked slope ${ }^{c}(\mathrm{GPa})$ & 364 & 10 & \\
\hline & & Cracked slope $^{c}(\mathrm{GPa})$ & 124 & 5 & \\
\hline
\end{tabular}

On the other hand, also in practical application a finishing painted layer is usually applied on mortar.

The surface temperature of both sides was monitored over the time by means of type $\mathrm{K}$ thermocouples until the Hot side of the wall reached a constant value. Moreover, the temperatures distribution on the entire surface of the samples was checked through a thermal camera (e.g. in Fig. 13). The environmental temperature was determined using a thermohygrometer placed around one meter far from the Cold side, it will be referred as Tout in the following. The emissivity of the surface of the specimens was measured involving a thermo-camera and placing a black adhesive tape of known emissivity on the surface itself [75]. The measurements were performed in an indoor laboratory, therefore the local 
Fig. 5 URM sample: a schematic (dimensions in $\mathrm{mm}$ ), $\mathbf{b}$ preparation and $\mathbf{c}$ overview

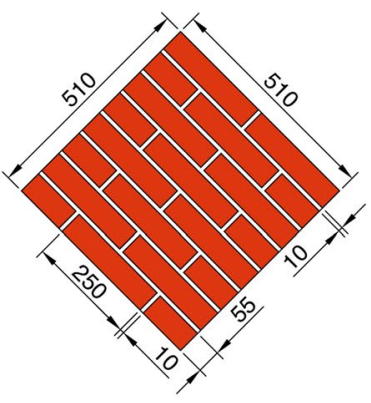

(a)

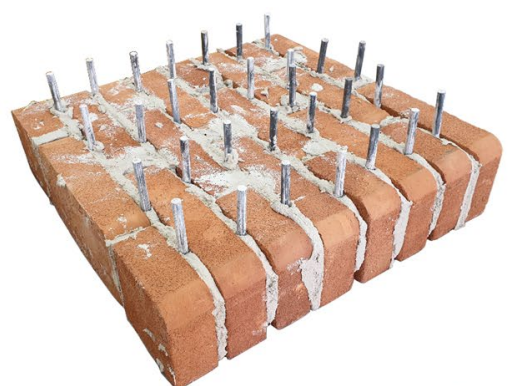

(b)

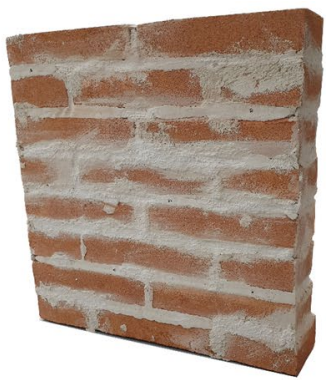

(c)
Fig. 6 NHL and GPM samples: a schematic view and $\mathbf{b}$ sample preparation

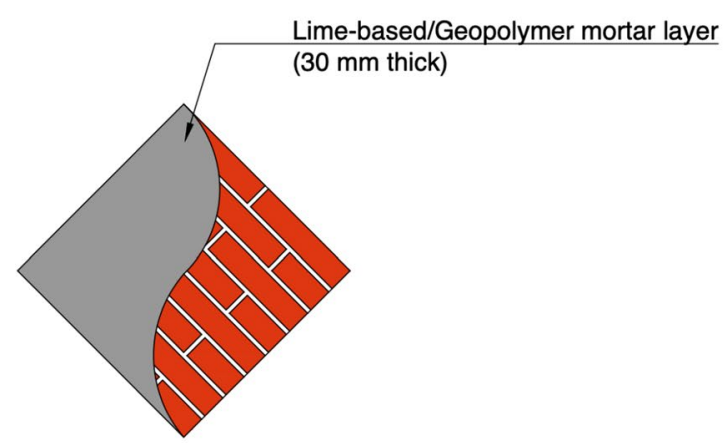

(a)

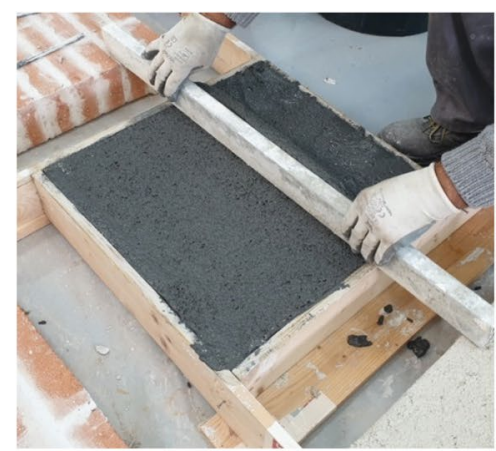

(b)

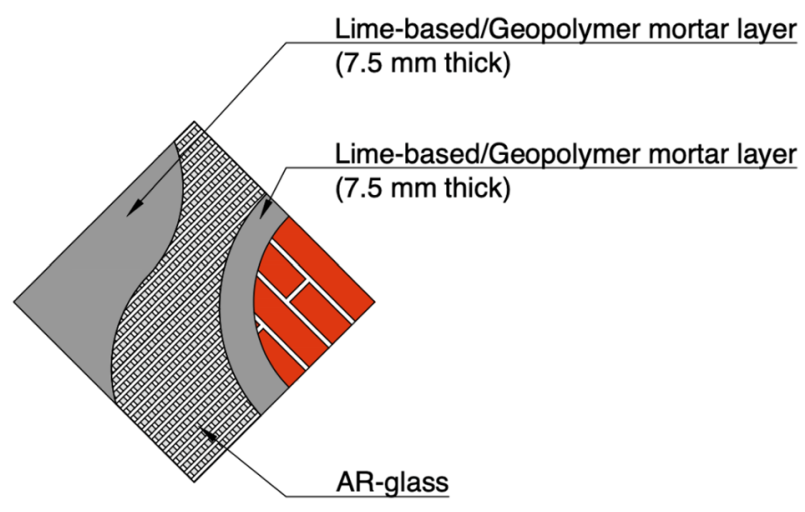

Fig. 7 Schematic view of FRCM/FRGM samples

wind velocity measured with the hot wire anemometer and in proximity of the wall was zero or even negligible. Hence, the convective heat transfer coefficient $\left(h_{c}\right)$, which depends directly on the air velocity in proximity of the wall, will be assumed equal to zero in the transmittance computation [76].

Finally, small fragments including both the matrix and the fabric were dried and investigated by Scanning Electron Microscope (SEM) in order to investigate the interface zone. Secondary electron micrographs were acquired at $15 \mathrm{eV}$ accelerating voltage, 35 spot size and $11 \mathrm{~mm}$ working distance (JEOL 6010LA SEM).

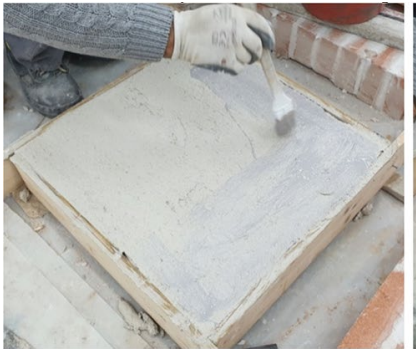

(a)

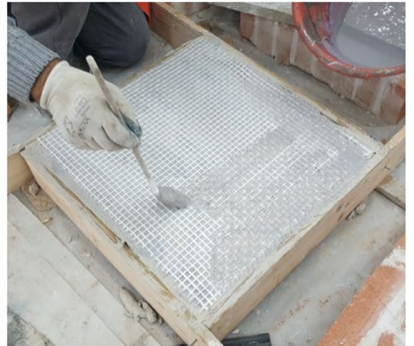

(b)
Fig. 8 Application of the adhesion promoter $\mathbf{a}$ before and $\mathbf{b}$ after the fabric installation

\section{Results and discussion}

\subsection{Shear strengthening}

The shear strength $\left(\tau_{\max }\right)$ was computed in all cases as the $\sqrt{ } 2 / 2$ of the maximum load $\left(P_{\max }\right)$ divided by the net crosssection of the masonry $\left(A_{n}=510 \times 120 \mathrm{~mm}^{2}\right)$, as reported in Eq. (1), [77]. The shear strain $(\gamma)$ was calculated as the sum of the vertical and the horizontal deformations in absolute value (according to measures of the vertical and the horizontal LVDT in Fig. 11) as reported in Eq. (2), [77]. In particular, the ultimate strain $\left(\gamma_{u}\right)$ corresponds to sample fragile failure or to a stress drop of $20 \%$ with respect to the shear strength. The 
Fig. 9 CRM/CRGM samples: a schematic view and b sample preparation

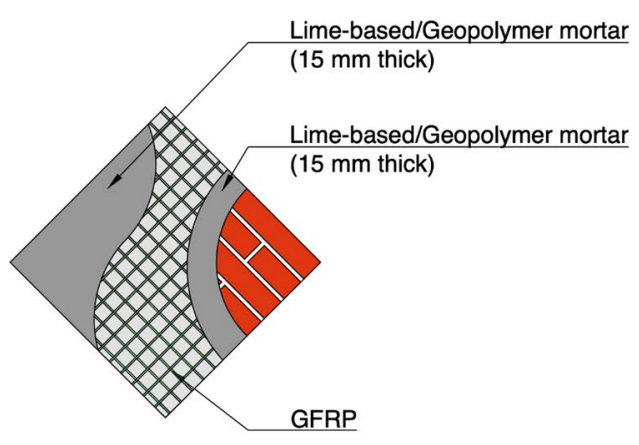

(a)

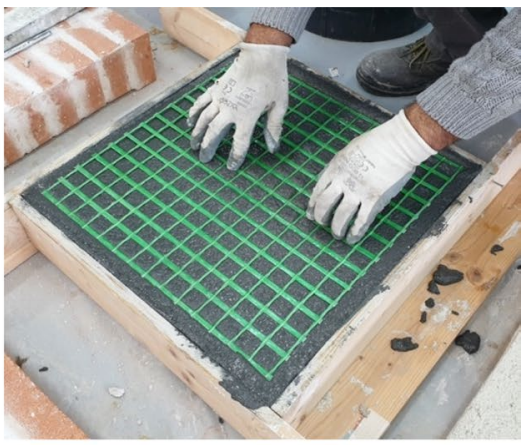

(b)
Fig. 10 SRG/SRGG samples: a schematic view and b sample preparation

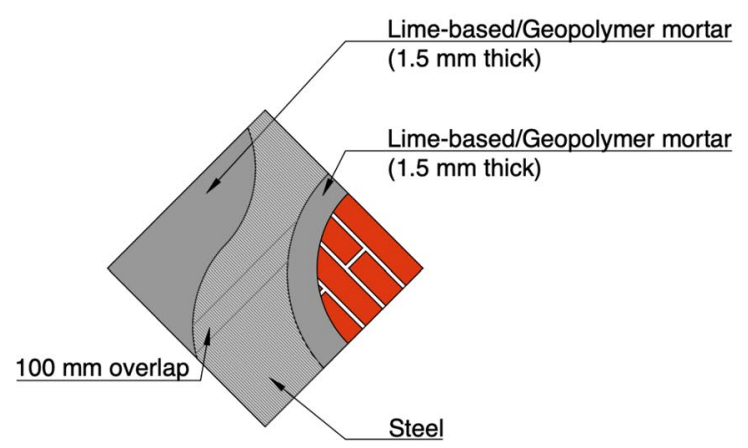

(a)

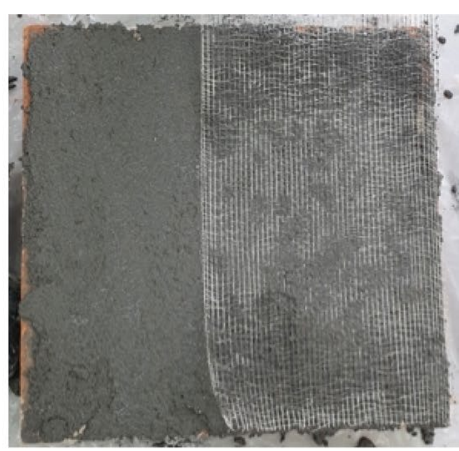

(b)
Fig. 11 Diagonal shear test setup (dimensions in $\mathrm{mm}$ ) [77]
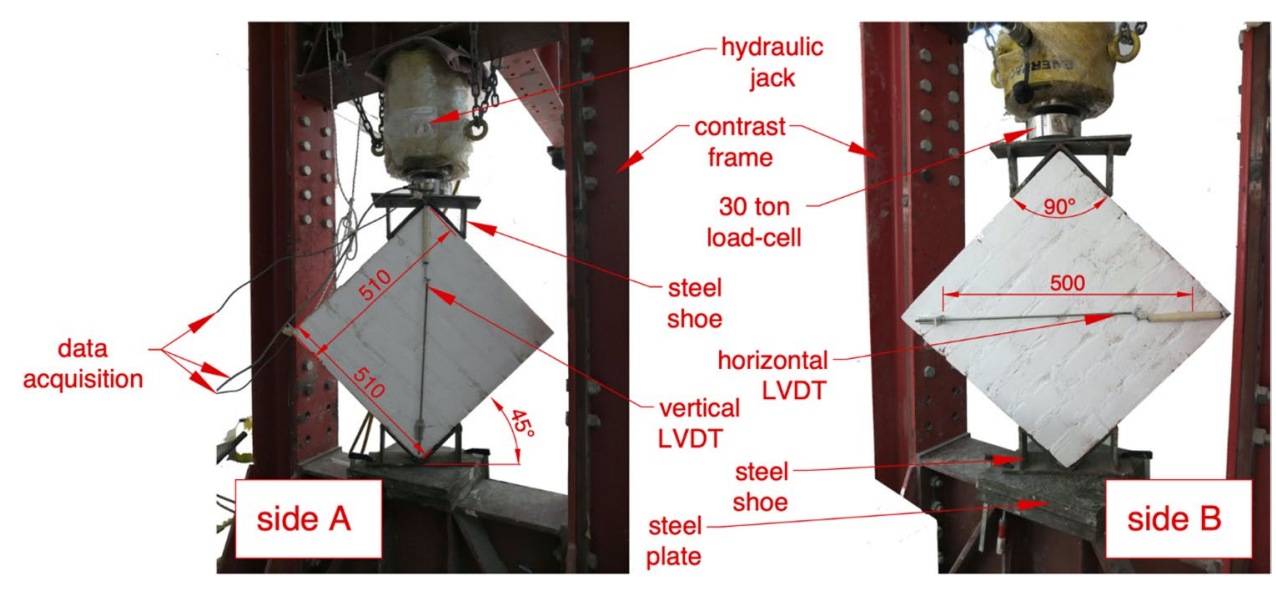

shear elastic modulus $(G)$ was herein assumed equal to the slope of the secant crossing the two points corresponding to the $5 \%$ and the $40 \%$ of the shear strength, as shown in Eq. (3). Since the test has been performed in load control the slope of the post-peak branch may be less accurate with respect to the initial one. Lastly, the ductility $(\mu)$ was calculated equal to the percentage scatter between the ultimate strain $\left(\gamma_{u}\right)$ and the strain corresponding to the shear strength $\left(\gamma_{\max }\right)$, according to Eq. (4).

$$
\begin{aligned}
& \tau_{\max }=\frac{\sqrt{2}}{2} \frac{P_{\max }}{A_{n}} \\
& \gamma=\frac{\left|\Delta_{\text {LVDT1 }}\right|+\left|\Delta_{\text {LVDT2 }}\right|}{\text { gaugelength }} \\
& G=\frac{\tau_{0.4-} \tau_{0.05}}{\gamma_{0.4}-\gamma_{0.05}}
\end{aligned}
$$




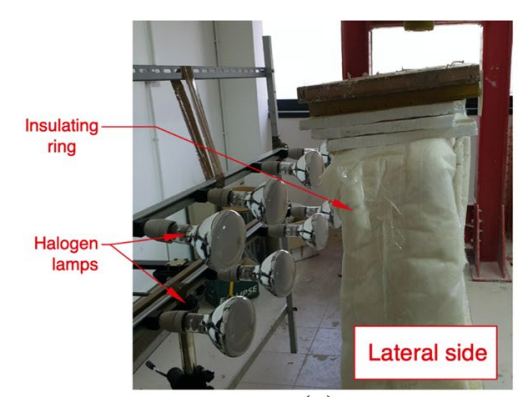

(a)

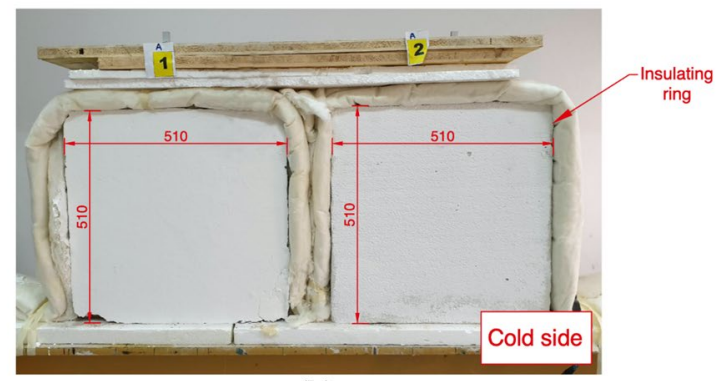

(b)

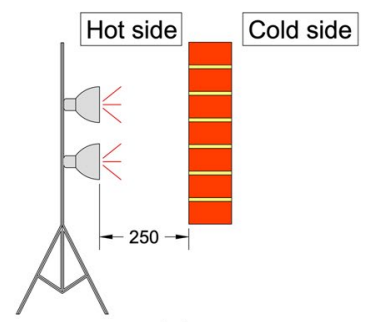

(c)

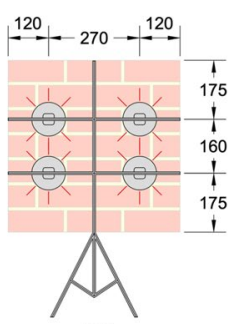

(d)
Fig. 12 Thermal test setup: a front view, b lateral view, c schematic lateral view and $\mathbf{d}$ schematic front view (dimensions in $\mathrm{mm}$ )

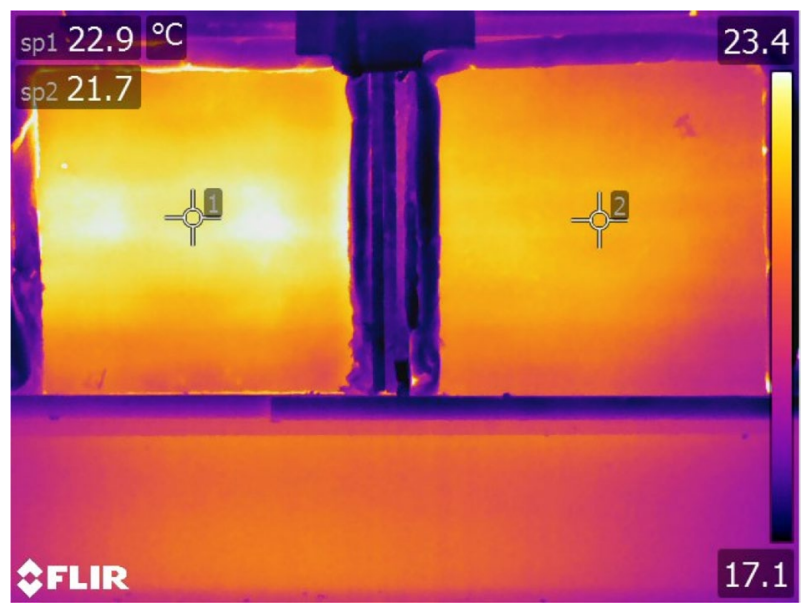

Fig. 13 Infrared thermography of a couple of specimens $\mu=\frac{\gamma_{u}-\gamma_{\max }}{\gamma_{\max }}$

The experimental outcomes in terms of mechanical performances of both the URM and retrofitted specimens are reported in the present section. Each sample is presented by means of its shear stress-strain curve and the schematic view of the cracking pattern (Fig. 14). Moreover, colored markers (Fig. 14s) were used to point out the curve's changes in slope linked to the crack development and failure modes. The same legend of colors was used on the schematic view of the samples in order to highlight the relative cracking pattern and/or the area related to detachment phenomena. The mean shear stress-strain curves, obtained for each couple of similar specimens, are reported in Fig. 15.

\subsubsection{URM (Un-Reinforced Masonry)}

The URM panels both manifested a brittle shear performance, as expected, with an almost linear behavior up to failure. URM-1 failed due to a single crack (red line and marker) mainly developed along one horizontal joint and the rupture of few bricks (Fig. 14a). It was noticed that the starting and ending points of the before mentioned crack was affected by the presence of the steel shoes, which caused a stress concentration at the angles of the panel during the last stages of load. In other words, the masonry panel split in two asymmetric parts which tended to slide past each other and push against the steel shoe. The maximum recorded stress was equal to $0.55 \mathrm{MPa}$.

URM-02 was again mainly affected by a sliding phenomenon (Fig. 14b). In this case, two cracks were clearly recognizable: the former was along a horizontal joint and firstly opened (red line and marker), the latter had a step-stair shape including both vertical and horizontal joints (green line and marker). In this case, the strength of the sample was $0.51 \mathrm{MPa}$. Despite the difference in cracking patterns of the two samples, the stress-strain curves recorded modest scatter (Fig. 15a). The mean values of shear strength, modulus and ultimate strain were all taken as reference to discuss the mechanical improvements of the retrofitted samples. (see Table 3).

\subsubsection{NHL (Natural Hydraulic Lime)}

In both the NHL panels a remarkable gain of the shear strength, which was found almost double with respect to the reference samples. Nonetheless, a substantial difference in shear strength between the two samples was recorded, as also evidenced by the different failure modes. In fact, NHL-1 (Fig. 14c) manifested a premature failure of one mortar layer, which suddenly full-detached (yellow marker 
Fig. 14 Shear stress vs strain curve $(\tau-\gamma)$ and cracking pattern of: a URM-1, b URM-2, c NHL-1, d NHL-2, e GPM-1, f GPM-2, g FRCM-1, h FRCM2, i FRGM-1, j FRGM-2, k CRM-1, I CRM-2, m CRGM-1, n CRGM-2, o SGR-1, p SRG-2, q SRGG-1, $\mathbf{r}$ SRGG-2 and $\mathbf{s}$ legend

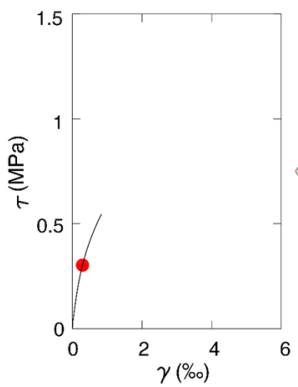

(a)

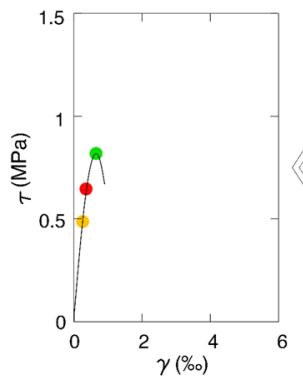

(c)

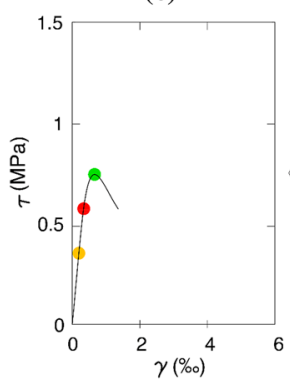

(e)

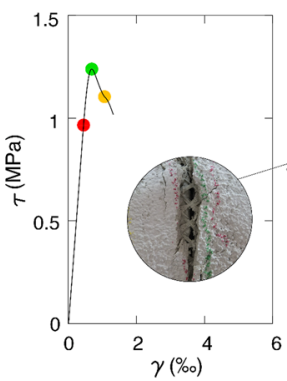

(g)

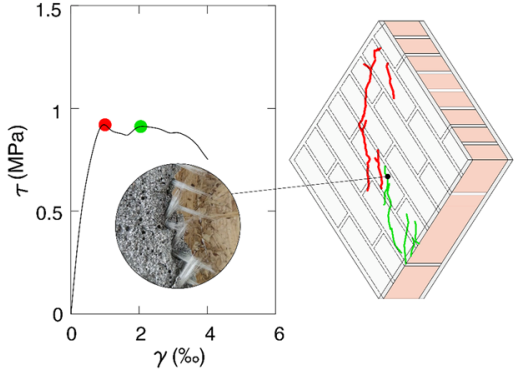

(i)

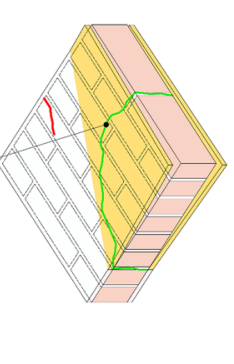

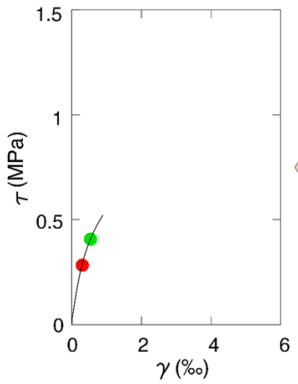

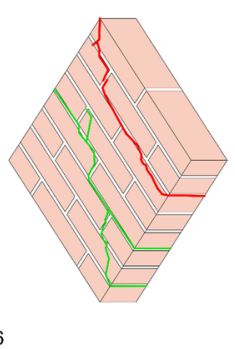

(b)
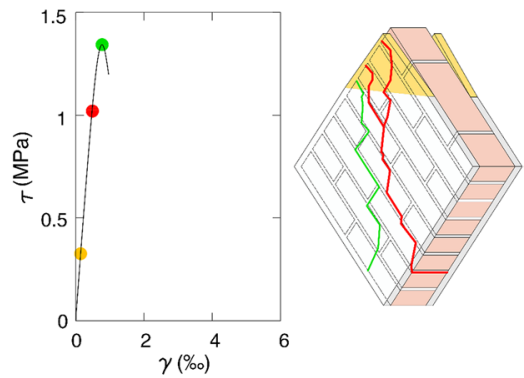

(d)

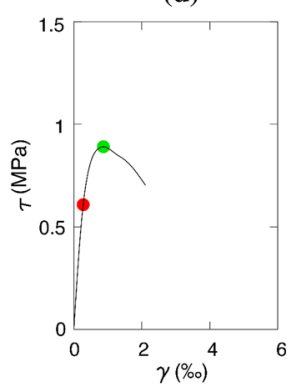

(f)

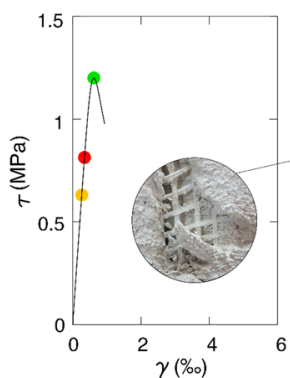

(h)

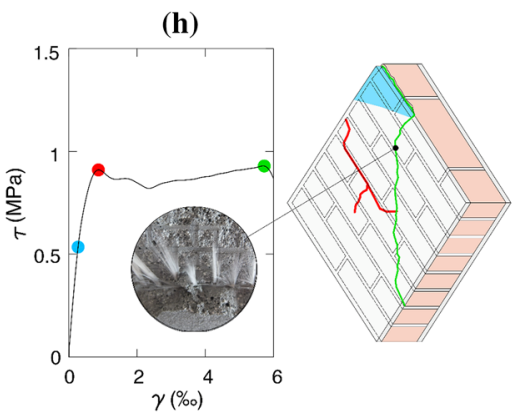

(j)
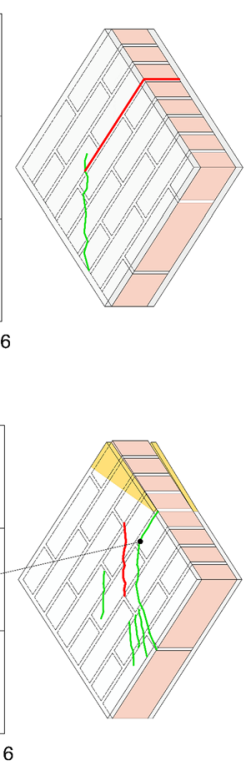
Fig. 14 (continued)

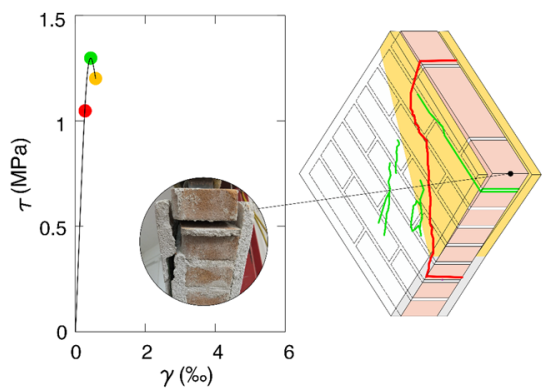

(k)
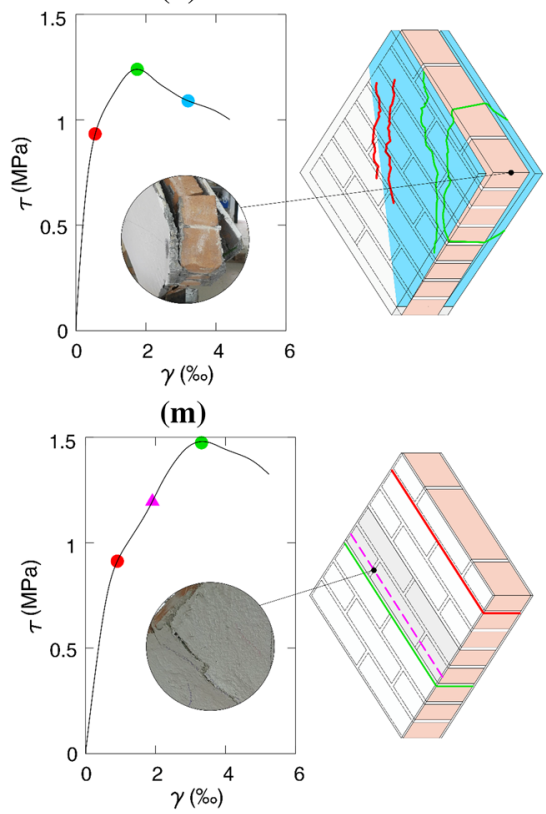

(o)

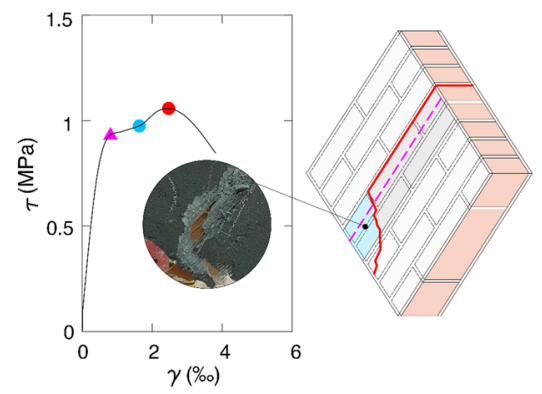

(q)

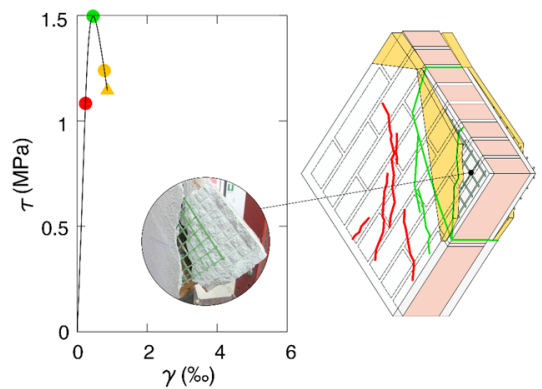

(1)

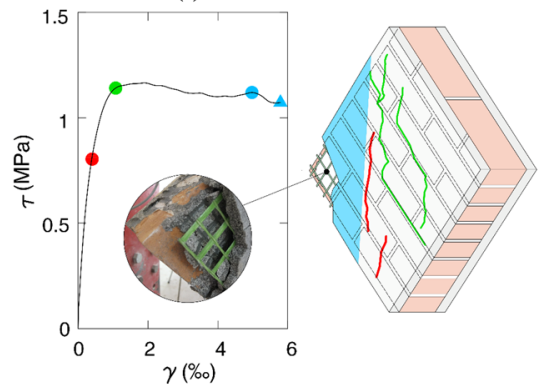

(n)

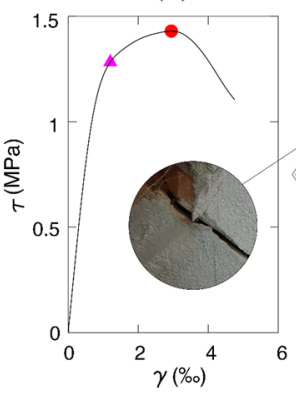

(p)

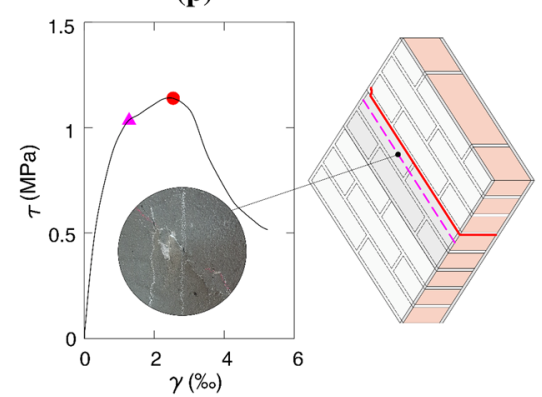

(r)

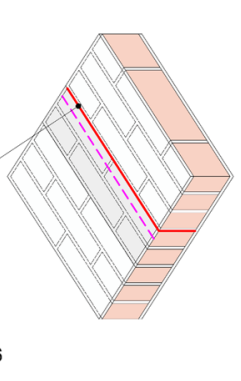




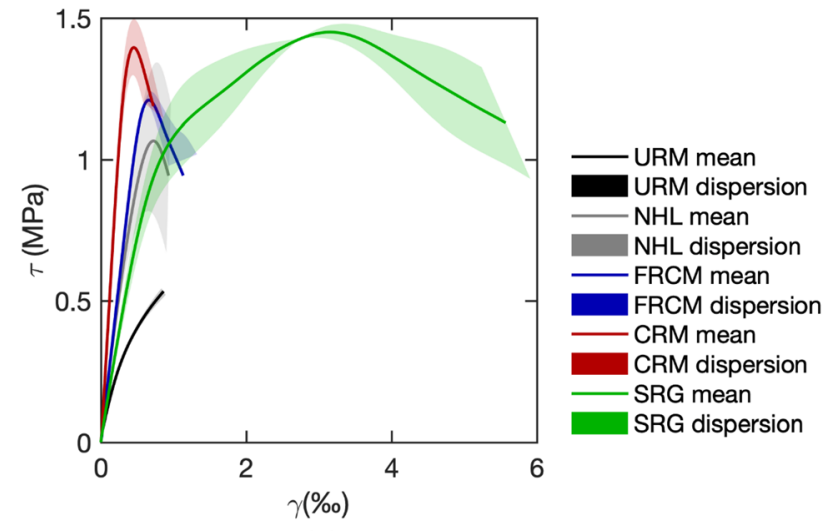

(a)

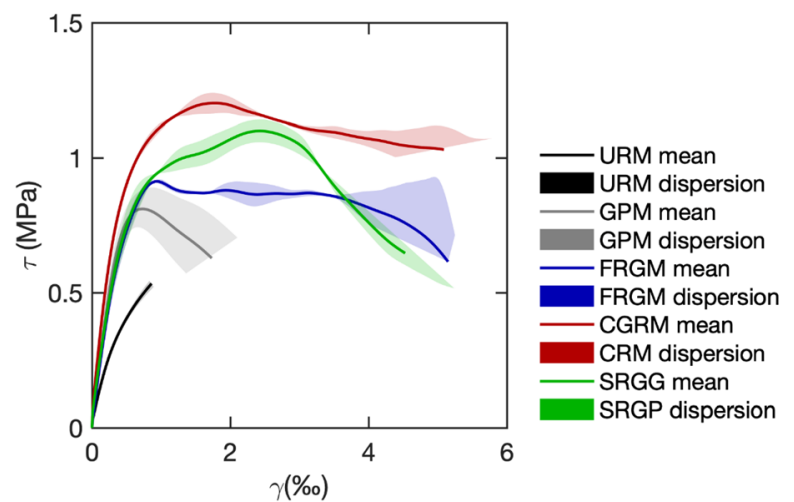

(b)

Fig. 15 Experimental shear stress vs shear strain curve $(\tau-\gamma)$ with relative scatter of: a URM, NHL, FRCM, CRM, SRG (a) and b URM, GPM, FRGM, CRGM, and SRGG and area) in correspondence of a shear-stress lower than URM mean shear strength $(0.53 \mathrm{MPa})$. Besides, the failure of the sample occurred due to the sliding phenomenon along the horizontal joint located at the middle of the panel (green marker and line), anticipated by a diagonal crack (red marker and line). Nonetheless, the shear strength recorded $(0.82 \mathrm{MPa})$ was higher than the one of URM.

In case of NHL-2, adhesive detachment phenomena locally interested the area close to the top steel shoe, at both sides (Fig. 14d). Again, the cracking pattern revealed a step-stair failure accountable to the loss of bond between brick and mortar. In this case, the shear strength reached 1.34 MPa. The experimental outcomes highlighted a poor adhesion between NHL-mortar and masonry substrate. Nevertheless, the mean curve (Fig. 15a) almost doubled the URM one in terms of shear strength and modulus. On the other hand, the increment of ductility was quite modest, about $30 \%$.

\subsubsection{GPM (GeoPolymer Mortar)}

The use of GPM-mortar proved to be efficient as retrofitting system. In fact, both the samples recorded a remarkable gain in terms of shear strength, stiffness and ductility. GPM revealed a crucial difference with respect to the NHL panels: the adhesion with the substrate was maintained also in the post-peak phase of the test, except for a very limited portion of plaster close to the top steel shoe for GPM-1 (Fig. 14e). In detail, GPM-1 exhibited two main step-stair

Table 3 Shear capacity, strength, modulus and ductility of the masonry panels

\begin{tabular}{|c|c|c|c|c|c|c|c|c|c|c|c|}
\hline & $\mathrm{V}(\mathrm{kN})$ & $\begin{array}{l}\left(\Delta_{\mathrm{LVDT} 1}+\Delta_{\mathrm{LVDT} 2}\right)_{\max } \\
(\mathrm{mm})\end{array}$ & $\begin{array}{l}\left(\Delta_{\text {LVDT1 }}+\Delta_{\text {LVDT2 }}\right)_{\text {ultimate }} \\
(\mathrm{mm})\end{array}$ & $\begin{array}{l}\tau \\
(\mathrm{MPa})\end{array}$ & $\begin{array}{l}\tau_{\mathrm{a}} \\
(\mathrm{MPa})\end{array}$ & $\begin{array}{l}\tau / \tau_{0} \\
(-)\end{array}$ & $\begin{array}{l}\mathrm{G} \\
(\mathrm{GPa})\end{array}$ & $\begin{array}{l}\mathrm{G}_{\mathrm{a}} \\
(\mathrm{GPa})\end{array}$ & $\begin{array}{l}\mathrm{G} / \mathrm{G}_{0} \\
(-)\end{array}$ & $\begin{array}{l}\mu \\
(\%)\end{array}$ & $\begin{array}{l}\mu_{\mathrm{a}} \\
(\%)\end{array}$ \\
\hline URM-1 & 47.96 & 0.415 & 0.415 & 0.554 & 0.533 & 1 & 0.841 & 0.817 & 1 & 0 & 0 \\
\hline URM-2 & 44.41 & 0.445 & 0.445 & 0.513 & & & 0.793 & & & 0 & \\
\hline NHL-1 & 70.81 & 0.325 & 0.459 & 0.818 & 1.081 & 2.03 & 1.55 & 1.844 & 2.26 & 43 & 32 \\
\hline NHL-2 & 116.25 & 0.385 & 0.480 & 1.343 & & & 2.137 & & & 21 & \\
\hline GPM-1 & 64.32 & 0.330 & 0.680 & 0.743 & 0.817 & 1.53 & 1.437 & 1.547 & 1.89 & 162 & 130 \\
\hline GPM-2 & 77.04 & 0.435 & 1.050 & 0.89 & & & 1.657 & & & 99 & \\
\hline FRCM-1 & 107.25 & 0.345 & 0.660 & 1.239 & 1.22 & 2.29 & 2.134 & 2.198 & 2.69 & 64 & 75 \\
\hline FRCM-2 & 103.88 & 0.305 & 0.465 & 1.2 & & & 2.262 & & & 85 & \\
\hline FRGM-1 & 79.72 & 0.485 & 2.005 & 0.921 & 0.917 & 1.72 & 1.387 & 1.47 & 1.8 & 431 & 516 \\
\hline FRGM-2 & 78.95 & 2.850 & 3.150 & 0.912 & & & 1.554 & & & 601 & \\
\hline CRM-1 & 112.36 & 0.220 & 0.290 & 1.298 & 1.398 & 2.62 & 3.936 & 4.27 & 5.23 & 32 & 61 \\
\hline CRM-2 & 129.58 & 0.290 & 0.430 & 1.497 & & & 4.612 & & & 91 & \\
\hline CRGM-1 & 107.34 & 0.870 & 2.195 & 1.240 & 1.203 & 2.26 & 2.386 & 2.43 & 2.97 & 155 & 181 \\
\hline CRGM-2 & 100.93 & 0.945 & 2.895 & 1.166 & & & 2.467 & & & 206 & \\
\hline SRG-1 & 128.11 & 0.395 & 2.620 & 1.480 & 1.455 & 2.73 & 1.344 & 1.50 & 1.84 & 348 & 318 \\
\hline SRG-2 & 123.79 & 0.500 & 2.955 & 1.430 & & & 1.662 & & & 288 & \\
\hline SRGG-1 & 91.58 & 0.395 & 1.905 & 1.058 & 1.100 & 2.06 & 1.955 & 1.81 & 2.22 & 305 & 330 \\
\hline SRGG-2 & 98.85 & 0.555 & 2.620 & 1.142 & & & 1.672 & & & 356 & \\
\hline
\end{tabular}


cracks developing in almost parallel direction: the former marked in red and the latter marked in green. The shear strength of GPM-1 was equal to $0.74 \mathrm{MPa}$.

Instead, GPM-2 failed due to a horizontal sliding (in red) and a few bricks rupture (in green), as shown in Fig. 14f. It can be remarked that the mortar has a significant contribution in the shear behavior of retrofitted masonry even in absence of internal reinforcement. The main contribution was in term of strength since the cracks manifested at higher load-level if compared with URM-series; in fact, only after the damage of the plaster a significant opening of the masonry joints occurred. The ductility of the specimen was also affected by the GPM-plaster (as for the NHL), even if relevant higher contribution was recorded in presence of internal mesh, as reported in the next sections. GPM-2 failed at a higher stress level (0.89 MPa), with respect to GPM-1.

Thus, by observing the average results (Fig. 15b and Table 3), the strength gain is lower, if compared to the one of NHL (53\% and 103\%, respectively). However, a higher ductility (about 130\%) was recognizable due to the more efficient adhesion between GPM-mortar and substrate.

\subsubsection{FRCM (Fabric Reinforced Cementitious Mortar)}

The FRCM-series was characterized by the premature adhesive detachment of the plaster from the substrate. This failure is similar to that already reported in the previous subsections. Nonetheless, the presence of glass fabric led to a higher gain in shear strength, modulus and ductility, with respect to NHL.

FRCM-1 exhibited a stiff linear branch up to the development of the first cracks (in red, Fig. 14g). In correspondence of the stress-peak (1.24 MPa), the panel cracked (in green) and, finally, the failure occurred with an adhesive detachment of the FRCM-system for a large portion of the sample (in yellow).

A similar behavior was recorded for FRCM-2 (Fig. 14h), even if the detachment phenomena occurred before the peak stress attainment (1.20 MPa) and along a more modest area. In both cases, the fabric in the cracks appeared uncut, as clearly displayed in Fig. 14g, h. As can be also appreciated from Fig. 15a and Table 3, the average ductility (about 75\%) is modest if compared with that obtained for GPM samples (about 130\%), even if the latter did not include any fabric. It is felt by the author that the fabric trended to slip within the matrix with negative implication on the strength and ductility. The glass mesh appeared to be distorted inside the crack, demonstrating an inadequate tensioning of the fibers, probably due to the sliding phenomenon. Thus, the crisis at the interfaces mortar-fabric and mortar-substrate both affected the mechanical performances.

\subsubsection{FRGM (Fabric Reinforced Geopolymer Mortar)}

The FRGM samples confirmed a substantial difference in the substrate/mortar bond with respect to the specimens retrofitted with a traditional system (i.e. lime-based mortar). In fact, the retrofitting system remained attached to the sample even at the ultimate damage stage. Also, the interaction between the fabric and the mortar appeared improved with respect to FRCM samples. In fact, the fabric visible through the cracks appeared broken, evidencing a better exploitation of its tensile performance (see Table 2).

FRGM-1 exhibited a large plateau after a quasi-linear phase up to the maximum stress $(0.92 \mathrm{MPa})$. A series of cracks along the diagonal of the panel characterized the crisis of the sample, as reported in Fig. 14i. Thus, the failure mode was governed by the diagonal cracking of the masonry instead of the mortar joint sliding (as observed for the specimens retrofitted with only the mortar). The panel acted as a strut in the vertical direction and a tie in the horizontal one. After the test ended, the FRGM layers were removed by means of hammering in order to observe the damage in the masonry. The FRGM was full attached to the masonry and the hammering isolated fragments of the retrofitting with portion of substrate on it, evidenced the high adhesion of the FRGM to the substrate.

FRGM-2 exhibited a similar behavior, with a local cohesive detachment of the reinforcing layer which occurred in the area near the top steel shoe (Fig. 14j). After the peak stress (0.91 MPa, red marker), a significant ductile behavior was observed, with a slightly hardening trend (Fig. 14j). The failure of the sample occurred when a diagonal crack formed and split the masonry in two portions (green marker). When the test ended, the fabric was visibly broken.

In conclusion, the mean shear strength reachable with FRGM-retrofitted samples, $0.92 \mathrm{MPa}$, was slightly lower if compared with FRCM-retrofitted ones, 1.22 MPa. Nonetheless, this series was significant in manifesting high ductility gain (Fig. 15b and Table 3), reaching a mean value equal to $516 \%$, probably related to the improved interaction between the mortar layer and the substrate, as well as between the fabric and the mortar.

\subsubsection{CRM (Composite Reinforced Mortar)}

The CRM demonstrated to be a very effective strengthening solution, as expected. In fact, the CRM-system was characterized by a thicker mortar layers (minimum $30 \mathrm{~mm}$ ) and a higher content of fibers per unit of length (along the side of the panel), besides a higher stiffness of the reinforcement since it is an FRP grid. However, the failure manifested very sudden involving both the substrate and the retrofitting system. 
CRM-1 exhibited an initial linear branch that gradually decreased its slope according to the formation of the first vertical crack, connecting the two steel shoes (in red), and the second crack in correspondence of the main diagonal (in green), as reported in Fig. 14k. The shear strength resulted equal to $1.30 \mathrm{MPa}$. The load bearing capacity was lost when the mortar layers detached in a brittle way, by adhesive failure at the interface between mortar and substrate. This detachment manifested symmetrically on both sides covering almost one third of the plaster surface (in yellow). Finally, the mortar was hammered and investigated to analyze the GFRP grid, which appeared undamaged.

CRM-2 exhibited a quite similar behavior. Again, two main diagonal cracks opened up to the peak stress $(1.50 \mathrm{MPa})$. After that, a residual strength was detected (Fig. 141). The failure of the sample was firstly dominated by the CRM detachment (yellow area) from the substrate and secondly by an expulsion involving the external layer of mortar (yellow triangle). The latter phenomenon was observed just in case of GFRP reinforcement. In fact, the stiffness of the GFRP grid is not negligible and plays a crucial role in promoting the split of the mortar layer when cracks open. The grid was deeply observed after the test and it wasn't found any trace of damage.

The mean values reported in Table 3 highlighted a considerable gain of shear strength (162\%) and modulus (423\%) with respect to URM, while the ductility was modest (61\%). The issue related to ductility is likely accountable to the poor adhesion of lime-based mortar with respect to the substrate, according to the experimental results.

\subsubsection{CRGM (Composite Reinforced Geopolymer Mortar)}

The CRGM reveled to be an efficient strengthening solution, as well. Nevertheless, a noteworthy difference in mechanical behavior can be recognized. It is interesting to notice that by utilizing the same reinforcement of the CRM-series, a different matrix produced a significant different behavior especially in terms of ductility. This aspect demonstrated the fundamental role of the matrix and of the matrix/fabric interface which need further investigations in order to consequently improve the available design models.

CRGM-1 showed a linear increase of the shear stress-strain relationship (Fig. 14m). This trend was modified when a group of thin diagonal cracks opened in the middle of the panel (in red). The load bearing capacity $(1.24 \mathrm{MPa})$ was compromised when a second group of cracks manifested close to one corner (in green). The residual strength in the post-peak branch was more significant if compared with the one of CRM-series. The failure of the sample was governed by the cohesive detachment of the retrofitting system from the masonry (light blue area). In particular, tangible pieces of clay brick remained bonded to the CRGM-retrofitting when it was fully taken off. The GFRP grid resulted undamaged.

Even more ductile was the behavior of the CRGM-2 sample, as reported in Fig. 14n and Table 3, while the pre-peak trend was very similar. The shear strength was recorded at $1.17 \mathrm{MPa}$. A relevant amount of energy was stored by the sample at increasing shear strain. Therefore, the failure was explosive and characterized by both the CRGM detachment and the expulsion of the external mortar layer at one corner. When the sample was demolished, the fabric was found undamaged and the GPM-matrix evidenced a cohesive bond with the substrate. The substrate-matrix appears to be the weakest interface even if in this case a cohesive failure within the substrate occurs instead of the adhesive failure registered for CRM samples.

\subsubsection{SRG (Steel Reinforced Grout)}

The SRG-system has the peculiarity of adopting a very thin mortar layer ( $3 \mathrm{~mm}$ per fabric layer according to the provider recommendation). In such a way, the direct contribution of the mortar to the shear strength is negligible. On the other hand, the matrix/fabric bond capacity is a crucial aspect. For this reason, the used matrix consists of a lime-based mortar including short fibers in order to limit the cracks opening. The manufacture provided a fabric roving with a $30 \mathrm{~cm}$ width. Consequently, an overlap $(10 \mathrm{~cm})$ was needed in order to cover the entire surface of the panel. This technical aspect had a mechanical consequence, since the overlap was centered with respect to the panel.

SRG-1 was the sample with the highest shear strength (1.48 MPa) due to both the high tensile strength of the steel fiber and its relevant equivalent thickness (Fig. 14o). The linearity of the shear stress versus strain relationship changed once the development of a crack along the top horizontal joint appeared (in red). After that, a progressive sliding was observed corresponding to the overlap of the fabric (magenta triangle). This last damage involved only the SRG-matrix. The peak was achieved in correspondence of the crack appearing at the joint in the middle of the specimen (in green). After the test, the panel was found split in three prismatic parts. Fabric was apparently not broken.

The SRG-2 had a linear initial trend up to higher load level if compared with SRG-1 (Fig. 14p). For this sample, the crisis at the overlap level was the first to manifest. Consequently, the two bodies near the opening slid past each other. The shear strength was equal to $1.43 \mathrm{MPa}$.

Definitely, the SRG-system did not fail by the masonry crush along the diagonal (i.e. compression line). The failure was dominated by sliding as for the URM, NHL and GPM series. The reason could be attributable to the steel fabric, which was unidirectional. Therefore, the absence of a mesh 
Fig. 16 Shear strength gain

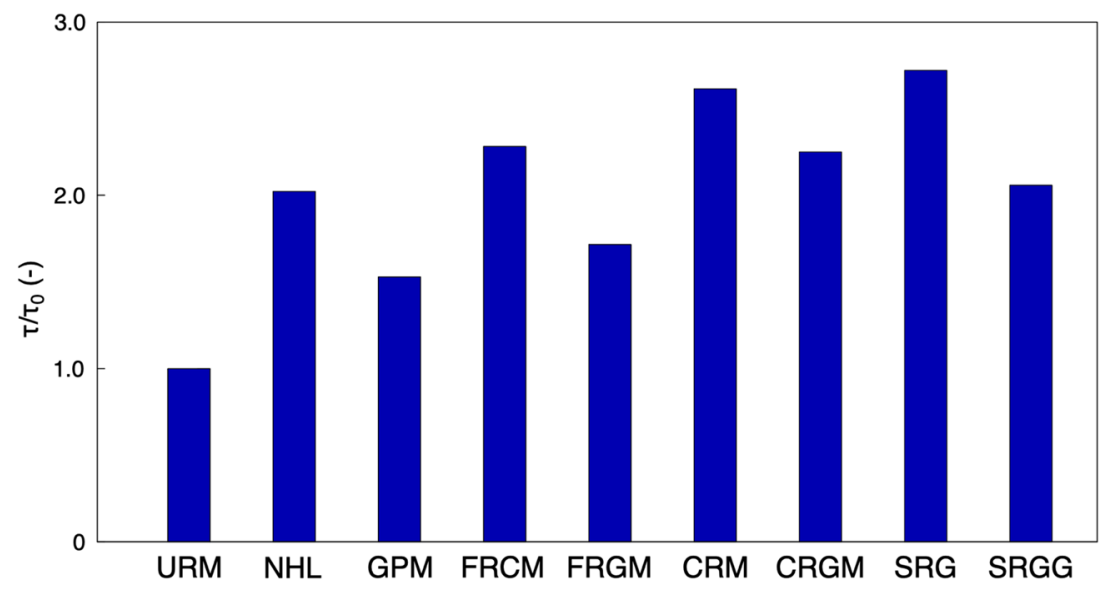

did not allow the formation of the strut and tie mechanisms within the masonry. The average curve in Fig. 15a and the results in Table 3 reveal a ductile behavior and a higher strength with respect to CRM and FRCM.

\subsubsection{SRGG (Steel Reinforced Geopolymer Grout)}

The specimens were manufactured in the same way of the SRG. The global behavior was comparable between SRG and SRGG showing relevant ductility and a collapse governed by sliding effect.

The SRGG-1, as reported in Fig. 14q, exhibited the first crisis at the overlap area. After that, a portion of external matrix detached (light blue) and the join sliding occurred. The failure of the retrofitting system was symmetric on both sides of the sample. The recorded peak of stress (1.06 $\mathrm{MPa}$ ) was lower if compared with the mean value of SRG (1.45 MPa). The SRGG-2 had a comparable performance in term of strength (1.14 MPa), ductility and global relationship (Fig. 14r). In fact, the average curve illustrated in Fig. 15b was close to the experimental outcomes. The main difference between SRG and SRGG was the level of load corresponding to the detachment at the overlap area, around 1.30 $\mathrm{MPa}$ and 1.00 $\mathrm{MPa}$, respectively. Therefore, the opening and sliding phenomena of SRGG occurred at lower stress level with respect to SRG. Contrastingly, similar values of ductility were reported in Table 3 for SRG and SRGG (i.e. $318 \%$ and $330 \%$, respectively).

\subsubsection{Comparison of strengthening systems}

The IMC-strengthened walls exhibited a different behavior, related to the properties of the involved materials, namely the masonry, the fabric/grid and the matrix. Moreover, the bond performance is a crucial aspect, depending on the interaction at different interfaces: masonry/matrix and matrix/ fabric. It is evident that the combination of materials may produces a large spectrum of different failures and structural response, in terms of shear strength, modulus and ductility. From the analytical point of view, the matrix contribution is generally neglected in the available formulations, while the possible interface crisis is taken into account by introducing the effective tensile stress of the IMC-system, which is determined according to the minimum value between the bond capacity and the tensile strength of the fabric [71]. In this sense, the proposed experimental investigation may contribute also to get a more insight into the mechanical behavior of masonry panels strengthened by IMC systems, and to suggest possible improvements of available design relationships.

The ratio between the average shear strength obtained for all the tested panels and that referred to unreinforced panels is summarized in Fig. 16. Firstly, it can be observed that the shear strength's gain obtained by using the innovative solutions (i.e. GPM, FRGM, CRGM and SRGG) was found significant, even if lower with respect to that registered for more traditional strengthening solutions (NHL, FRCM, CRM, SRG).

A relevant contribution of the matrix has been observed, when utilizing a significant thickness of mortar (i.e. $30 \mathrm{~mm}$ ); in fact, even in absence of fabric, both the NHL and GPM matrices produced a significant gain of the masonry shear strength. For instance, the presence of NHL-layers basically doubled the shear capacity of the URM panels. In presence of both matrix and fabric it is difficult to determine the contribution of each material, since the interaction at fabric/ matrix interface plays a relevant role. In any case, the fabric/mortar combination provided a further strength increment. In fact, the application of the FRCM led to a $129 \%$ gain of shear capacity with respect to NHL (103\%), with a halved mortar thickness Even with the presence of fabric, the geopolymer-based system exhibited a lower shear capacity gain (72\%). The CRM and SRG panels led to the highest shear strength gain, i.e. $162 \%$ and $173 \%$, respectively. For the former, the comparison with results obtained for NHL (same kind of mortar used as external layer and same 
Fig. 17 Shear modulus computed for masonry panels

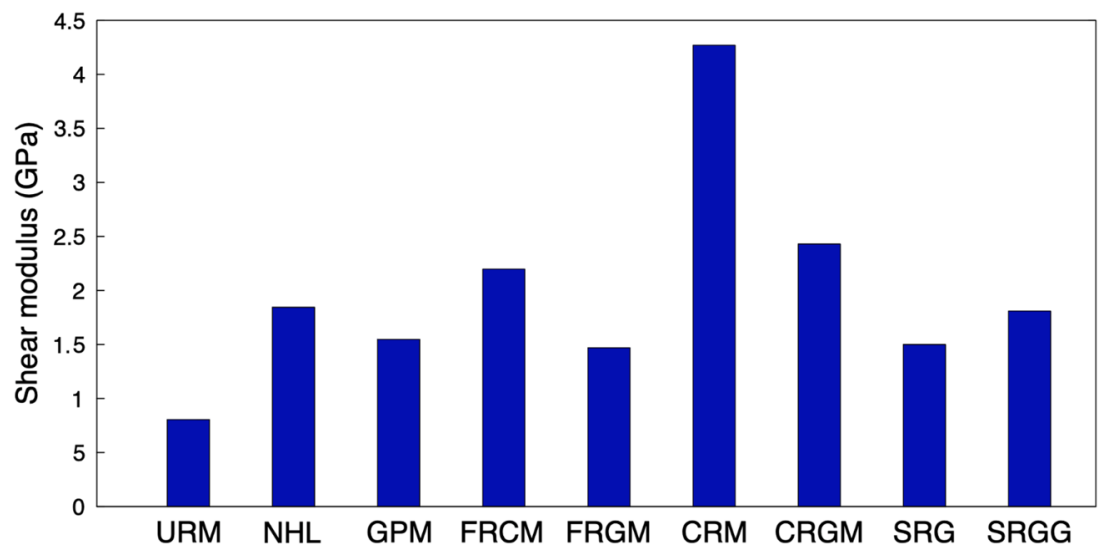

thickness) clearly evidenced the significant contribution of the GFRP grid. Referring to SRG, it should be evidenced that the combination of high-performance fibers with a specific matrix (HDM) furnished a relevant strength gain even with a very reduced mortar thickness $(3 \mathrm{~mm})$. The same reinforcement (GFRP and steel) used with the innovative mortar gave satisfactory results, i.e. $126 \%$ and $106 \%$ strength gain, respectively. Basically, the most performant systems in terms of shear strength were those involving the GFRP or steel fabric (i.e. CRM, CRGM, SRG and SRGG), due to the higher performances of the reinforcement, the thicker layer of mortar in the first cases, the improved interaction between reinforcement and mortar also of mechanical type, the improved adhesion between mortar and substrate in the case of the proposed GP matrix.

As regards the shear modulus, it was mainly affected by the stiffness of the matrix but also by the stiffness of the reinforcement and its capacity of stress distribution with consequent limitation of wide cracks opening at low load levels. This property was generally found lower for the innovative solutions, as reported in Fig. 17. In fact, NHL and GPM panels almost doubled stiffness when compared with URM ones. Even with a half matrix thickness, FRCM and FRGM manifested shear modulus values similarly to NHL and GPM, respectively, thanks to the presence of the fabric.
Moreover, for the stiff GFRP grid combined with a thicker mortar layer (CRM and CRGM samples) the highest values in terms of shear modulus were recorded (4.27 GPa and 2.43 GPa, respectively). The initial stiffness of SRG and SRGG is mainly related to the fabric, with a negligible contribution of matrix, that has been used with a very narrow thickness.

All the retrofitted samples manifested a relevant ductility, as clearly showed in Fig. 18, more evident when the geopolymer matrix was utilized. In fact, NHL samples exhibited a quite moderate ductility (32\%), while GPM ones manifested a higher ductility (130\%), even in absence of fabric. Also, in case of IMC retrofitting, the effect of the mortar on the ductility can be appreciated; the ductility value resulted equal to $75 \%, 516 \%, 61 \%$ and $181 \%$ for FRCM, FRGM, CRM and CRGM samples, respectively. Significant and comparable ductility values were found for SRG (318\%) and SRGG (330\%), likely due to the specific fiber-reinforced mortar (HDM) involved in SRG-system. In fact, the fibers within the mortar mix are aimed to enhance the ductility of the mortar itself.

The results in terms of ductility are strictly linked to the observed cracking patterns and failure modes. The use of GPM-based reinforcement demonstrated a larger shear strain capacity with respect to the NHL-based ones,
Fig. 18 Ductility computed for masonry panels

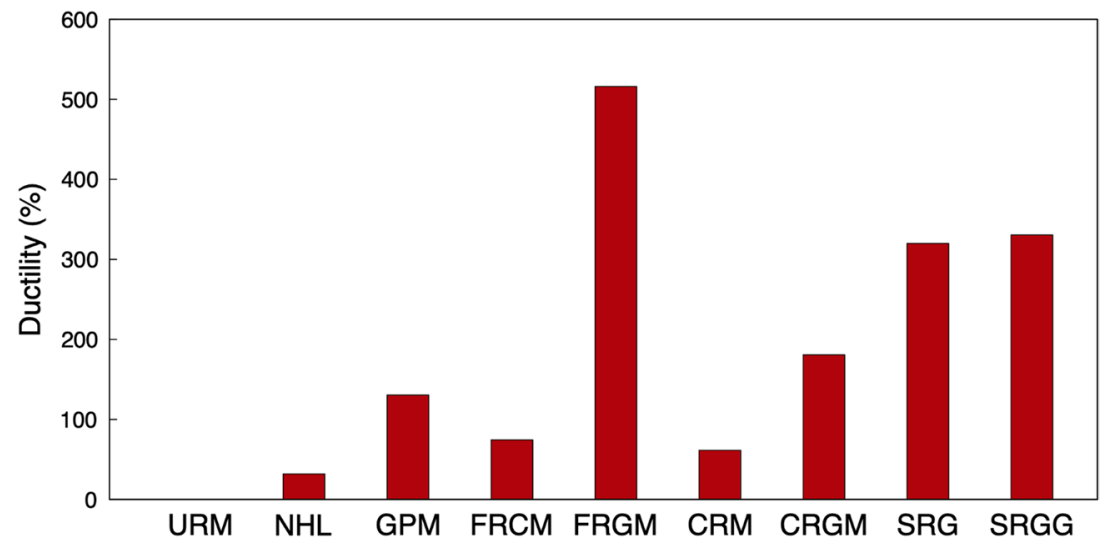


Fig. 19 Cracking patterns of a FRCM and b FRGM

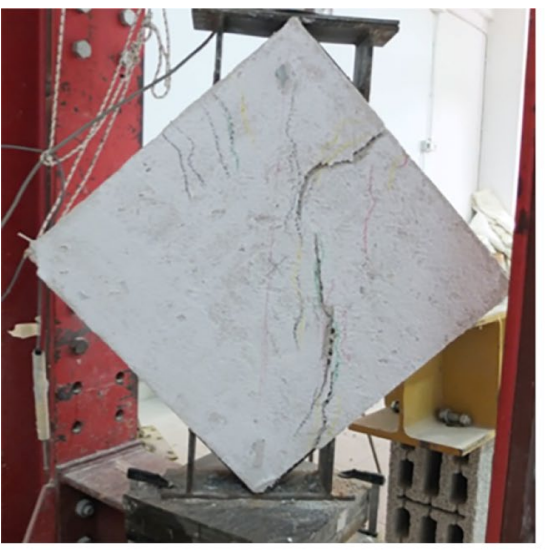

(a)

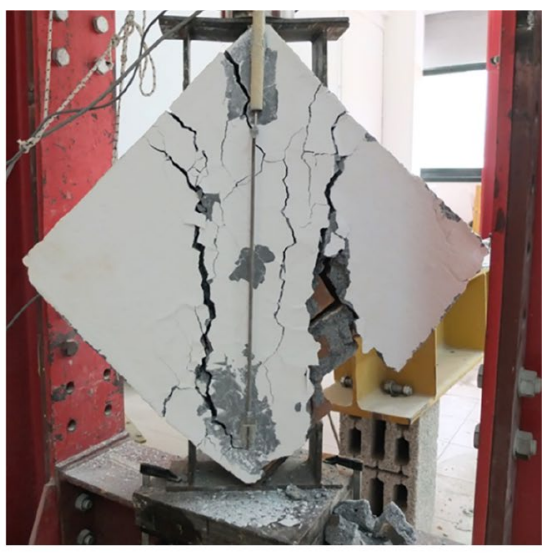

(b)
Fig. 20 Adhesive detachment of a CRM and cohesive detachment of $\mathbf{b}$ CRGM

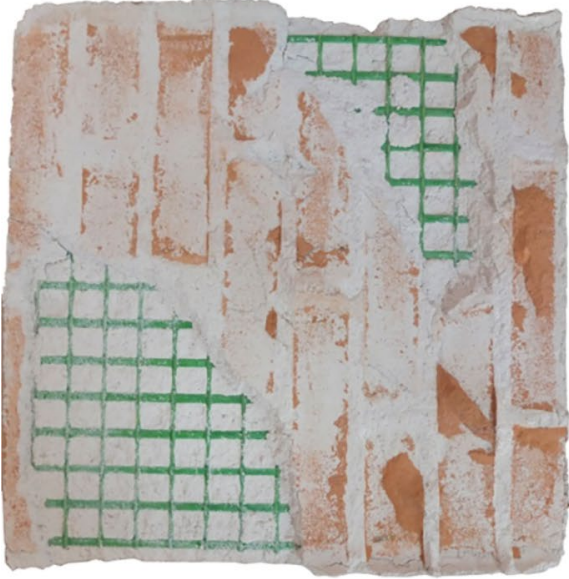

(a)

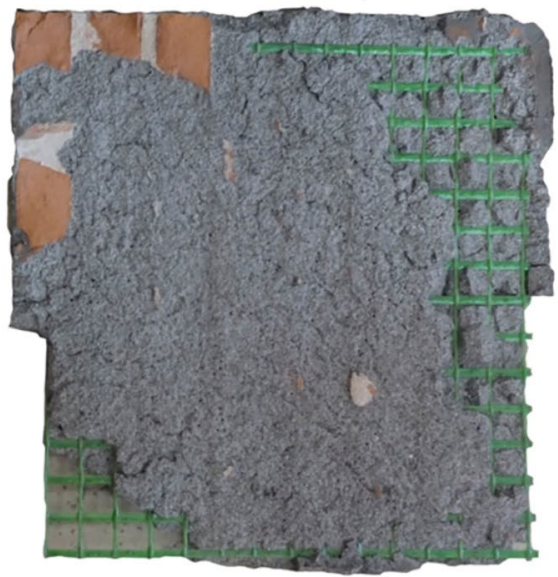

(b) because micro-cracks opened progressively within the entire reinforced surface, as illustrated in Fig. 19.

To sum up, the proposed geopolymer-based systems showed a lower shear strength when compared to the relative lime-based systems; while an improved masonry/ matrix and matrix/fabric interaction was observed, responsible of the observed higher ductility values, as already reported in the previous section. For instance, Fig. 20a illustrates a typical adhesive detachment of NHL-based samples from the substrate, while Fig. 20b reports the cohesive detachment of GPM-based samples from the substrate, testified by deep portions of clay bricks on CRGM surface, in contrast with the superficial patina found on the CRM surface.

\subsection{Energy retrofitting}

A thermal test, focused on evaluating the difference in temperature profiles once the steady state is reached, was conducted for all the specimens as previous described. The thermal transmittance $U$ was computed in relation to the experimental set-up, according to Ref. [78], as stated in Eqs. (5)-(6). The so-computed experimental results cannot be considered as the precise transmittance values, in absolute terms. Nonetheless, the aim of the investigation is to compare the relative thermal characteristic of the specimens, therefore the performed measures can be considered effective for that scope.

$$
\begin{aligned}
& R^{\prime}=\frac{T_{w h}-T_{w c}}{5.67 \varepsilon_{\text {tot }}\left[\left(\frac{T_{w c}}{100}\right)^{4}-\left(\frac{T_{\text {out }}}{100}\right)^{4}\right]+h_{c}\left(T_{w c}-T_{\text {out }}\right)} \\
& U=\frac{1}{R_{\text {int }}+R^{\prime}+R_{\text {ext }}}
\end{aligned}
$$

where:

- $R^{\prime}$ is the thermal resistance of the wall;

- $R_{\text {int }}$ is the contribution of internal convective resistance $\left(0.13 \mathrm{~m}^{2} \mathrm{~K} \mathrm{~W}^{-1}\right)$; 


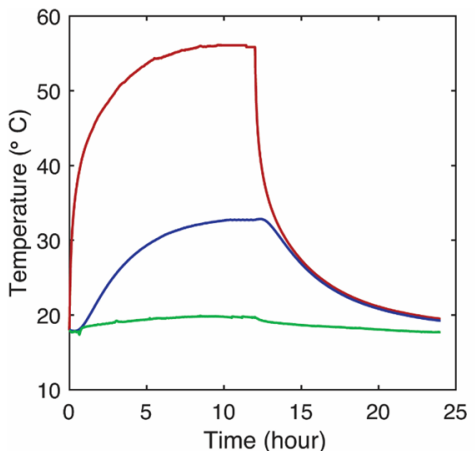

(a)

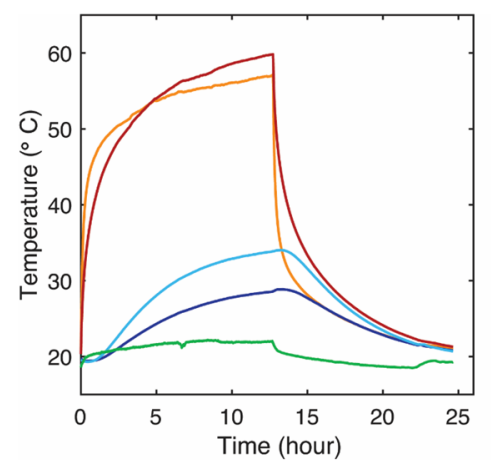

(c)

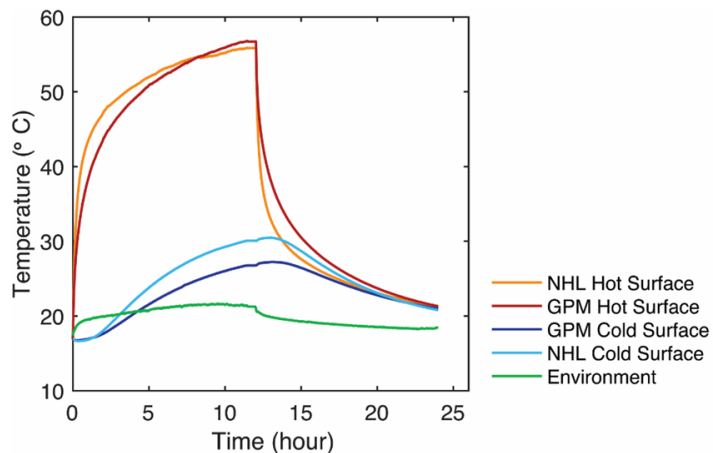

(b)

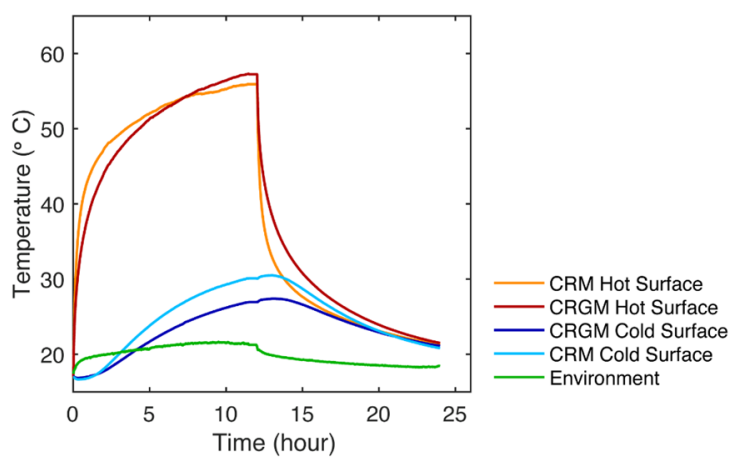

(d)

Fig. 21 Temperature profiles on both sides of: a URM, b NHL vs GPM, $\mathbf{c}$ FRCM vs FRGM and d CRM vs CRGM

- $R_{\text {ext }}$ is the contribution of external convective resistance $\left(0.04 \mathrm{~m}^{2} \mathrm{~K} \mathrm{~W}^{-1}\right)$;

- $T_{w h}$ is the surface temperature referred to the hot side of the wall;

- $T_{w c}$ is the surface temperature referred to the cold side of the wall;

- $\varepsilon_{t o t}$ is the emissivity of the wall, assumed equal to 0.93 ;

- $T_{\text {out }}$ is the environmental temperature, as previous discussed;

- $\mathrm{h}_{\mathrm{c}}$ is the convective heat transfer coefficient, here assumed equal to zero, as previous discussed;

- $U$ is the thermal transmittance of the wall.

\subsubsection{URM}

The URM samples were tested in order to establish a reference benchmark, recording surfaces temperatures for $24 \mathrm{~h}$ (roughly $12 \mathrm{~h}$ to heat the sample and $12 \mathrm{~h}$ to let it cool down). In Fig. 21a, the results related to URM thermal test are reported. In particular, the red line represents the hot surface's temperature, i.e. the surface exposed to halogen lamps. This curve reached a maximum at $\sim 56^{\circ} \mathrm{C}$, before dropping down in the cooling stage. On the other hand, the blue curve shows the temperatures recorded at the cold surface. The curve started growing after $\sim 1 \mathrm{~h}$, when the heat flow reached the cold side of the wall. Even the decline of temperature (at $\sim 12 \mathrm{~h}$ ) manifested a modest delay with respect to the red curve, due to the well-known relevant thermal inertia of the masonry [79]. Finally, the green curve draws the environment temperature versus the time during the test. The value of environment temperature (referred as $\mathrm{T}_{\text {out }}$ in Eq. 5) was utilized in thermal transmittance computation.

\subsubsection{NHL vs GPM}

NHL and GPM results were arranged in the same graph (Fig. 21b) in order to compare the thermal behavior of the specimens during the test. Again, the orange and red curves represent the hot side of NHL and GPM, respectively. While, the blue and cyan ones represent the cold side of GPM and NHL, respectively. In the heating stage, NHL exhibited a faster increase of temperature up to the peak $\left(\sim 56{ }^{\circ} \mathrm{C}\right)$, with respect to GPM. Nonetheless, the latter reached a higher temperature $\left(\sim 57^{\circ} \mathrm{C}\right)$ at steady-state condition. In the cooling stage, both the specimens exhibited a delay in the decrease phase of the curve, which took longer time with respect to URM. Thus, the thermal inertia of the wall was increased by applying the mortar layer. The difference recorded between the peaks of cyan and 
Table 4 Surface temperature, thermal resistance and transmittance of the masonry panels

\begin{tabular}{lllllll}
\hline & $\begin{array}{l}\mathrm{T}_{\mathrm{wh}} \\
\left({ }^{\circ} \mathrm{C}\right)\end{array}$ & $\begin{array}{l}\mathrm{T}_{\mathrm{wc}} \\
\left({ }^{\circ} \mathrm{C}\right)\end{array}$ & $\begin{array}{l}\mathrm{T}_{\mathrm{out}} \\
\left({ }^{\circ} \mathrm{C}\right)\end{array}$ & $\begin{array}{l}\mathrm{R}^{\prime} \\
\left(\mathrm{m}^{2} \mathrm{~K} \mathrm{~W}^{-1}\right)\end{array}$ & $\begin{array}{l}\mathrm{U} \\
\left(\mathrm{W} \mathrm{m}^{-2} \mathrm{~K}^{-1}\right)\end{array}$ & $\begin{array}{l}\mathrm{U} / \mathrm{U}_{0} \\
(-)\end{array}$ \\
\hline URM & 56.13 & 32.85 & 19.60 & 0.310 & 2.082 & 1.00 \\
NHL & 56.79 & 30.48 & 20.60 & 0.474 & 1.554 & 0.75 \\
GPM & 55.87 & 27.23 & 20.60 & 0.781 & 1.051 & 0.50 \\
FRCM & 59.83 & 34.03 & 21.83 & 0.367 & 1.862 & 0.89 \\
FRGM & 57.13 & 28.85 & 21.83 & 0.718 & 1.126 & 0.54 \\
CRM & 57.83 & 30.65 & 20.71 & 0.473 & 1.555 & 0.75 \\
GRM & 56.17 & 27.47 & 20.76 & 0.771 & 1.063 & 0.51 \\
\hline
\end{tabular}

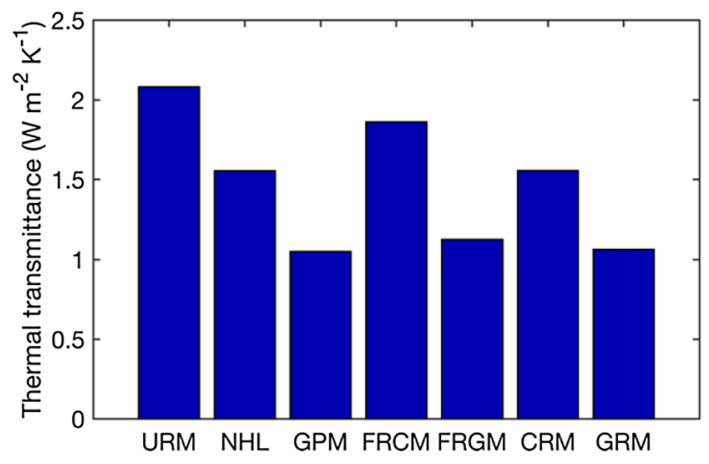

Fig. 22 Thermal transmittance of the samples

blue curves suggests that a substantial change in thermal behavior is obtained.

\subsubsection{FRCM vs FRGM}

A comparison between temperature profiles on both sides of FRCM and FRGM is reported in Fig. 21c. The behavior of the curves is similar to those in Fig. 21b, despite different values were recorded. The orange curve (FRCM) reached a peak at $\sim 57{ }^{\circ} \mathrm{C}$, while the red one (FRGM) exhibited a slower increase, up to $\sim 60^{\circ} \mathrm{C}$. The blue curve drew the cooling stage of FRGM and the cyan one of FRCM, exhibiting a small increase (due to thermal inertia) before the decrease in temperature. Even in this case, the cyan and blue curves exhibited a difference linked to different thermal transmittance.

\subsubsection{CRM vs CRGM}

CRM and CRGM results (Fig. 21d) substantially confirmed the ones obtained with NHL and GPM (Fig. 21b). As expected, the presence of the GFRP mesh can be neglected in terms of thermal transmittance. The orange and red curves (hot side of CRM and CRGM, respectively) and the blue and cyan ones (cold side of CRM and CRGM, respectively) exhibited a very small scatter with respect to the curves of NHL and GPM. Even in this case, the lime-based solution exhibited a fast increase up to the peak-temperature $\left(\sim 56^{\circ} \mathrm{C}\right)$, even if the geopolymer-based one reached a higher temperature $\left(\sim 57^{\circ} \mathrm{C}\right)$ at steady-state condition.

\subsubsection{Comparison of energy retrofitting systems}

The so-collected data were used to compute the thermal resistance and transmittance of the wall according to Eqs. 5-6. All the values are reported in Table 4. A thermal transmittance equal to $2.082 \mathrm{~W} \mathrm{~m}^{-2} \mathrm{~K}^{-1}$ was estimated for URM. The lime-based retrofitting systems exhibited lower thermal transmittances, equal to $1.862 \mathrm{~W} \mathrm{~m}^{-2} \mathrm{~K}^{-1}$ (FRCM) and $1.554 \mathrm{~W} \mathrm{~m}^{-2} \mathrm{~K}^{-1}$ (NHL). Thus, the application of a layer which is not generally oriented to thermal insulation can lead to a thermal transmittance reduction, as shown in Fig. 22. In fact, the FRCM and NHL manifested a reduction of $11 \%$ and $25 \%$, respectively. Conversely, geopolymer-based retrofitting systems are prone to be adopted for an integrated system, aimed to improve both thermal capacity and mechanical resistance. A thermal transmittance equal to $1.126 \mathrm{~W} \mathrm{~m}^{-2} \mathrm{~K}^{-1}$ was computed for FRGM and equal to $1.051 \mathrm{~W} \mathrm{~m}^{-2} \mathrm{~K}^{-1}$ for GPM. Indeed, FRGM and GPM exhibited a greater reduction of thermal transmittance of $46 \%$ and $50 \%$, respectively with respect to URM panels. As already discussed, CRM and CRGM highlighted that the thermal contribution of the fabric can be neglected, which is a useful information for energy retrofitting design purposes.

\subsection{SEM analysis}

To gain more insight into the fabric/matrix interface behavior, the SEM electron micrographs were acquired in the secondary electron (SE) with a magnification equal to 500 $\mathrm{X}$ (FRGM, FRCM, CRM and CRGM) and $100 \mathrm{X}$ (SRG and SRGG). Basically, the inorganic matrix is less able 
Fig. 23 SEM micrographs of a FRCM, b FRGM, c CRM, d CRGM, e SRG and f SRGG

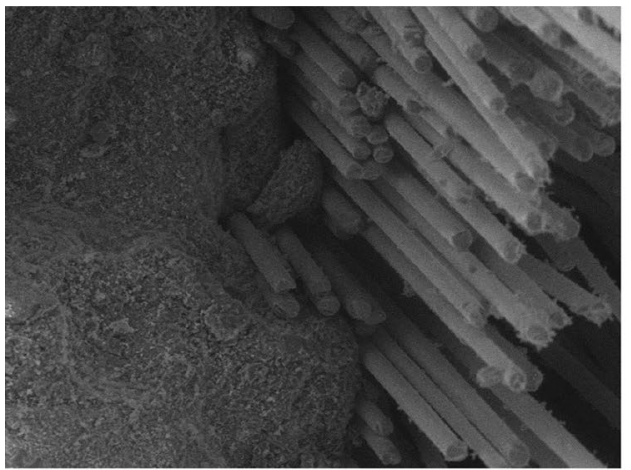

(a)

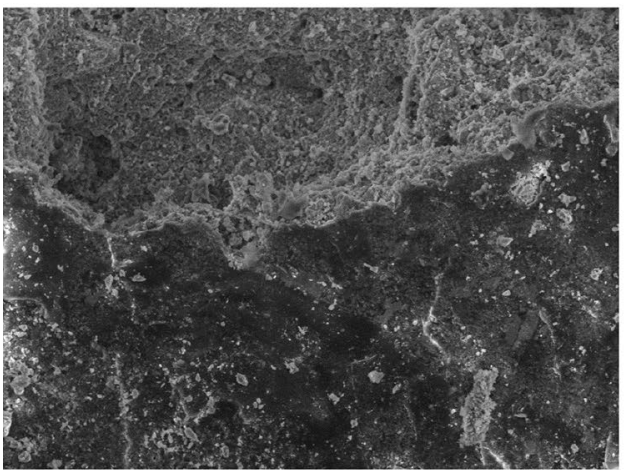

(c)

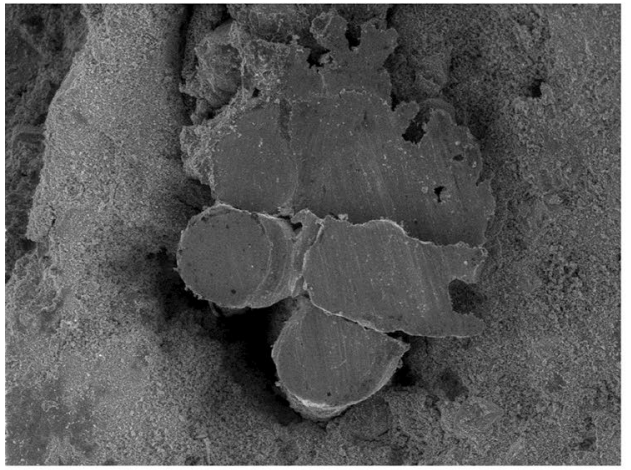

(e)

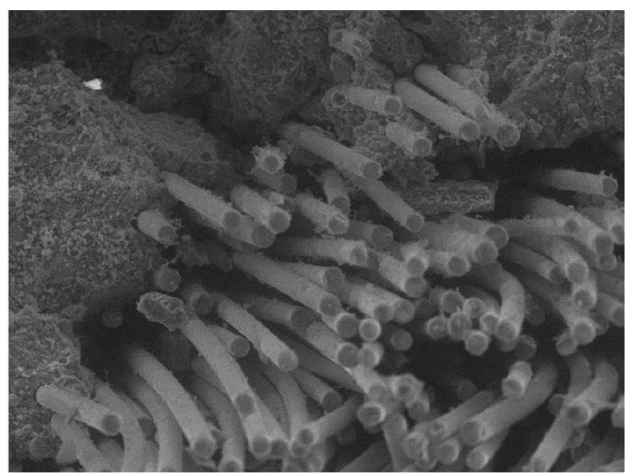

(b)

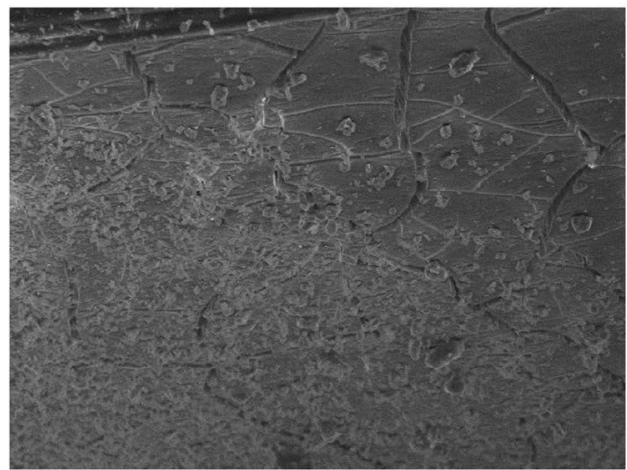

(d)

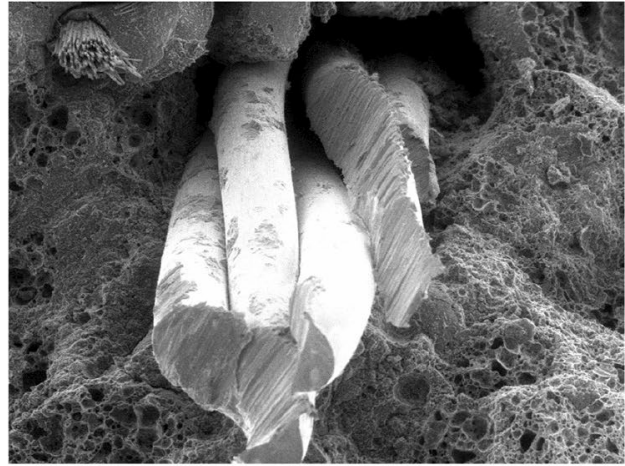

(f) to impregnate the fiber (differently from the epoxy-based resin commonly used in FRP). The bond is mainly due to the mechanical contribution developed by the matrix passing through the grid voids and getting in contact with the exposed surface of the fibers [80]. However, an adhesion contribution is also offered, depending on the kind of matrix. The substantial difference in adhesion contribution can be addressed to the different chemical compounds within the binder of the mortars and, consequently, to the different hydration products [59].

The micrographs of FRCM (Fig. 23a) and FRGM (Fig. 23b) reveled a fundamental difference in the matrix/ fabric interaction. In case of FRCM, the fabric and the limebased matrix appears two clearly different phases with a very limited contact area, mainly involving the external surface of the yarns. On the contrary, the FRGM-matrix appears able to penetrate within the yarns, guarantying a larger contact area, with the matrix surrounding at least the whole lateral surface of the external filaments. This capacity is probably related to the small particle size of the fly ash. This observation confirmed the role of the geopolymer-matrix outlined in the previous paragraphs. In fact, the FRGM was more ductile and allowed a better stress transfer within the fibers (they were found cut after the test).

In case of CRM-like systems, the bond adhesion was related to the contact between the organic matrix and the inorganic one (matrix of the GFRP grid). The SEMimages of CRM and CRGM are illustrated in Fig. 23c and $\mathrm{d}$, respectively. It was noticed that the CRM-grid was fully detached from the lime-based matrix and only the external film of resin remained on the inorganic matrix (darker zone in Fig. 23a). On the other hand, the adhesion between the 

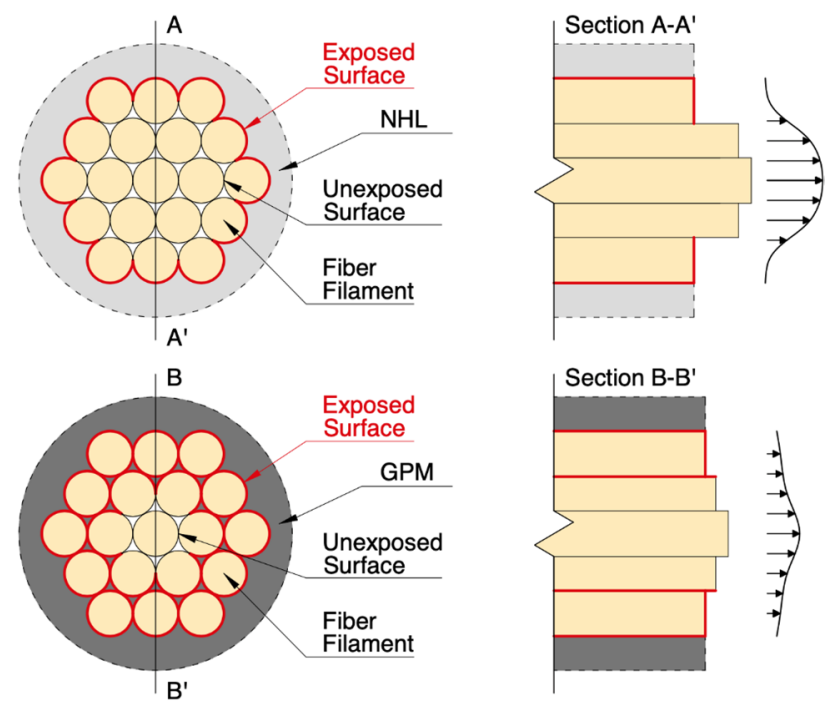

Fig. 24 Matrix versus fabric's filaments interaction in tensile stress state: FRCM (top) and FRGM (bottom)

matrix and the grid seems improved in the case of CRGM. In fact, the inorganic matrix reduced its contact with the grid more gradually, as testified by the particles of geopolymer on the pre-impregnated fibers shown in Fig. 23b.

Finally, the micrographs of SRG and SRGG are illustrated in Fig. 23e and f, respectively. The contact surface of the samples was the same in all cases; likewise, a similar behavior (especially for the ductility) was recorded in the mechanical tests of SRG and SRGG.

If the matrix/masonry interaction is easy to realize because it depends essentially on the roughness of the masonry and the chemical adhesion capacity of the matrix, the matrix/fiber interaction is more complex since it requires micro-scale analysis. In the uncracked stage, the matrix demonstrated to affect significantly the strength of the plastered masonry. When the matrix is cracked, the further shear strength gain is mainly guaranteed by the fabric. In this case, the ductility is more or less evident depending on the interaction between matrix and reinforcement. For example, when dealing with steel or GFRP fabric, the yard is a compact element with high stiffness; thus, the interaction with the matrix is manly of mechanical type. On the other hand, when considering dry glass mesh the yard is composed by numerous filaments placed side-by-side and clearly distinguishable in the $500 \times$ zoom in. Thus, the matrix impregnation is more possible.

The SEM pictures evidenced how this impregnation depends on the type of matrix, as also illustrated in the draft of Fig. 24. In fact, by considering the same glass fiber yard, the GPM was found to be more in contact with the filaments because the geopolymer nature of the matrix (i.e. less viscous than the lime-based mortar and assessed with smaller particles) allowed the confinement of the externally-placed filament (see Fig. 23b) and to reach a partial exposed surface of few internal filaments. This capacity was definitely not attributable to the NHL-matrix which covered a more limited exposed surface consisting on the perimeter of the filament's group or rather the lateral surface of the yard (see again Fig. 24). For this reason, the tensioning of the filaments was found different between FRCM and FRGM. The former exhibited a significant sliding of the core filaments with respect to the border one. The latter showed a more uniform behavior, with a consequent more uniform distribution of stresses within the filaments. For this reason, when the matrix was cracked the GPM-based IMC-retrofitting was able to provide larger ductility to the masonry.

\section{Conclusions}

The experimental investigation presented in this paper is focused on fired clay brick masonry panels retrofitted with different IMC-systems. The main aim was to compare the mechanical and thermal performances of the different retrofitted samples. At this scope, commercially available IMC products were used and evaluated in comparison with similar systems obtained by replacing the matrix with a new geopolymer-based mortar with improved thermal properties.

The following remarks can be pointed out:

1. The mechanical tests evidenced that geopolymer-based systems lead to a similar shear capacity gain with respect to the traditional ones, despite a lower initial shear modulus was found. Moreover, a higher ductility improvement in case of geopolymer-based IMCs was recorded. In particular, the sample retrofitted with the traditional FRCM-system exhibited a ductility value equal to $75 \%$, while the installation of the innovative solution, namely FRGM, led to a ductility value equal to $516 \%$.

2. All the geopolymer-based IMCs manifested a much higher thermal insulation potential with respect to the traditional systems. Comprehensibly, the biggest scatter in thermal resistance ratio ( 25\%) was recorded comparing the thicker IMC-systems, i.e. NHL vs. GPM and CRM vs. CRGM. For example,

3. SEM analysis was involved to better understand the mechanical behavior of the fabric/matrix interface. As already mentioned, the geopolymer-based IMCs led to a considerable ductility improvement. This outcome was also related to the micro-structural interaction of substrate, matrix and fabric. Through SEM micrographs a larger exposed area (i.e. the contact surface between the matrix and the fibers) was detected for FRGM system, which is accountable for the higher level of impregna- 
tion. The combined analysis of mechanical test and SEM images evidenced as a higher level of impregnation leads to a higher exploitation of fabric at the post-peak stage and, consequently, to a higher ductility. Further investigations are suggested in order to better understand the fabric/matrix bonding

The results obtained in this experimental campaign seem very promising, the progress of the research in this topic will allow to validate the founds herein reported and furnish reliable indications for design purposes.

Acknowledgements The research presented in this article was funded by the Italian Ministry of University and Research in the framework of the national project PRIN (Progetti di ricerca di Rilevante Interesse Nazionale—Bando 2017)—Project PRIN SURMOUNT "Innovative systems based on inorganic mortar and non metallic reinforcement for the upgrade of masonry structures and non structural elements". The authors would like to acknowledge Dennert Poraver GmbH and BASF SE for providing materials to this research.

Funding Open access funding provided by Università del Salento within the CRUI-CARE Agreement.

\section{Declarations}

Conflict of interest On behalf of all authors, the corresponding author states that there is no conflict of interest.

Open Access This article is licensed under a Creative Commons Attribution 4.0 International License, which permits use, sharing, adaptation, distribution and reproduction in any medium or format, as long as you give appropriate credit to the original author(s) and the source, provide a link to the Creative Commons licence, and indicate if changes were made. The images or other third party material in this article are included in the article's Creative Commons licence, unless indicated otherwise in a credit line to the material. If material is not included in the article's Creative Commons licence and your intended use is not permitted by statutory regulation or exceeds the permitted use, you will need to obtain permission directly from the copyright holder. To view a copy of this licence, visit http://creativecommons.org/licenses/by/4.0/.

\section{References}

1. Gkournelos DP, Bournas DA, Triantafillou TC (2019) Combined seismic and energy upgrading of existing buildings using advanced materials, EUR 29172 EN, Publications Office of the European Union, Luxembourg. ISBN 978-92-79-81824-0, https:// doi.org/10.2760/17376, JRC111303

2. European Union. Directive 2012/27/EU of the European Parliament and of the Council of 25 October 2012 on Energy Efficiency, Amending Directives 2009/125/EC and 2010/30/EU and Repealing Directives 2004/8/EC and 2006/32/EC. Brussels, 14 November 2012. https://eur-lex.europa.eu/legal-content/EN/TXT/?uri= celex\%3A32012L0027. Accessed Apr 2021

3. Nanni A (2003) North American design guidelines for concrete reinforcement and strengthening using FRP: principles, applications and unresolved issues. Constr Build Mater 17(6-7):439-446
4. Al-Saadi NTK, Mohammed A, Al-Mahaidi R, Sanjayan J (2019) A state-of-the-art review: Near-surface mounted FRP composites for reinforced concrete structures. Constr Build Mater 209:748-769

5. Aiello MA, Cascardi A, Ombres L, Verre S (2020) Confinement of masonry columns with the FRCM-system: theoretical and experimental investigation. Infrastructures 5(11):1-14. https:// doi.org/10.3390/infrastructures5110101

6. Ombres L, Verre S (2020) Analysis of the behavior of FRCM confined clay brick masonry columns. Fibers. https://doi.org/ 10.3390/fib8020011

7. Ombres L, Verre S (2019) Numerical modeling approaches of FRCMs/SRG confined masonry columns. Front Built Environ. https://doi.org/10.3389/fbuil.2019.00143

8. Aiello MA, Cascardi A, Ombres L, Verre S (2020) Open issue for confinement of masonry column with FRCM system: theoretical and experimental investigation. Paper presented at the REHABEND, 2121-2129

9. Koutas BLN, Tetta Z, Bournas DA, Triantafillou TC (2019) Strengthening of concrete structures with textile reinforced mortars: state-of-the-art review. J Compos Constr 23(I):1-43

10. Del Zoppo M, Di Ludovico M, Prota A (2019) Analysis of FRCM and CRM parameters for the in-plane shear strengthening of different URM types. Compos B Eng 171:20-33

11. Butler M, Mechtcherine V, Hempel S (2010) Durability of textile reinforced concrete made with AR glass fibre: effect of the matrix composition. Mater Struct 43(10):1351-1368

12. Parisi F, Iovinella I, Balsamo A, Augenti N, Prota A (2013) In-plane behaviour of tuff masonry strengthened with inorganic matrix-grid composites. Compos B Eng 45(1):1657-1666

13. Del Zoppo M, Di Ludovico M, Balsamo A, Prota A (2019) Inplane shear capacity of tuff masonry walls with traditional and innovative Composite Reinforced Mortars. Constr Build Mater 210:289-300

14. De Lorenzis L, Galati N, Ombres L (2004) In-plane shear strengthening of natural masonry walls with NSM CFRP strips and FRCM overlay. In: Structural Analysis of Historical Constructions-2 Volume Set: Possibilities of Numerical and Experimental Techniques-Proceedings of the IVth Int. Seminar on Structural Analysis of Historical Constructions, 10-13 November 2004, Padova

15. Mantegazza G, Gatti A, Barbieri A (2006) Retrofitting concrete and masonry building: FRCM (fiber reinforced cementitious matrix) a new emerging technology. XII Konferencja NaukowoTechniczna Problemy Remontowe W Budownictwie Ogólnym i Obiektach Zabytkowych REMO, 6-8

16. Prota A, Marcari G, Fabbrocino G, Manfredi G, Aldea C (2006) Experimental in-plane behavior of tuff masonry strengthened with cementitious matrix-grid composites. J Compos Constr 10(3):223-233

17. Faella C, Martinelli E, Nigro E, Paciello S (2010) Shear capacity of masonry walls externally strengthened with a cementbased composite material: an experimental campaign. Constr Build Mater 24(1):84-93

18. Babaeidarabad S, De Caso F, Nanni A (2014) URM walls strengthened with fabric-reinforced cementitious matrix composite subjected to diagonal compression. J Compos Constr 18(2):04013045

19. Balsamo A, Iovinella I, Morandini G (2014). FRG strengthening systems for masonry building. In: NZSEE Conference

20. Corradi M, Borri A, Castori G, Sisti R (2014) Shear strengthening of wall panels through jacketing with cement mortar reinforced by GFRP grids. Compos B Eng 64:33-42

21. Ismail N, Ingham JM (2014) Polymer textiles as a retrofit material for masonry walls. Proc Inst Civil Eng Struct Build 167(1):15-25 
22. Koutas L, Triantafillou TC, Bousias SN (2015) Analytical modeling of masonry-infilled RC frames retrofitted with textile-reinforced mortar. J Compos Constr 19(5):04014082

23. Almeida JA, Pereira EB, Barros JA (2015) Assessment of overlay masonry strengthening system under in-plane monotonic and cyclic loading using the diagonal tensile test. Constr Build Mater 94:851-865

24. Gattesco N, Boem I (2015) Experimental and analytical study to evaluate the effectiveness of an in-plane reinforcement for masonry walls using GFRP meshes. Constr Build Mater 88:94-104

25. Gattesco N, Boem I, Dudine A (2015) Diagonal compression tests on masonry walls strengthened with a GFRP mesh reinforced mortar coating. Bull Earthq Eng 13(6):1703-1726

26. Menna C, Asprone D, Durante M, Zinno A, Balsamo A, Prota A (2015) Structural behaviour of masonry panels strengthened with an innovative hemp fibre composite grid. Constr Build Mater 100:111-121

27. Balsamo A, Asprone D, Iovinella I, Maddaloni G, Menna C, Prota A et al (2016) Effectiveness of inorganic matrix-grid composites for strengthening masonry walls. In: Brick and Block Masonry. CRC Press, pp 2013-2020

28. Borri A, Corradi M, Sisti R, Buratti C, Belloni E, Moretti E (2016) Masonry wall panels retrofitted with thermal-insulating GFRPreinforced jacketing. Mater Struct 49(10):3957-3968

29. Ferretti F, Incerti A, Ferracuti B, Mazzotti C (2016) Diagonal compression tests on masonry panels strengthened with FRP and FRCM. In: Proc. of the 10th SAHC Conference, vol 13. Lueven, p 15

30. Micelli F, Sciolti MS, Leone M, Aiello MA, Dudine A (2016) Shear behaviour of Fiber Reinforced Mortar strengthened masonry walls built with limestone blocks and hydraulic mortar. In: da Porto, Valluzzi (eds) Brick and Block Masonry-Trends, Innovations and Challenges-Modena

31. Yardim Y, Lalaj O (2016) Shear strengthening of unreinforced masonry wall with different fiber reinforced mortar jacketing. Constr Build Mater 102:149-154

32. Ferretti F, Incerti A, Ferracuti B, Mazzotti C (2017) FRCM strengthened masonry panels: the role of mechanical anchorages and symmetric layouts. In: Key Engineering Materials, vol 747. Trans Tech Publications Ltd. pp 334-341

33. Ismail N, El-Maaddawy T, Najmal A, Khattak N (2017) Diagonal tension testing of as-built and fabric reinforced cementitious matrix strengthened masonry panels. In: Proceedings of the 16th World Conference of Earthquake Engineering (16WCEE), Chile, pp 9-13

34. Marcari G, Basili M, Vestroni F (2017) Experimental investigation of tuff masonry panels reinforced with surface bonded basalt textile-reinforced mortar. Compos B Eng 108:131-142

35. Mustafaraj E, Yardim Y (2018) In-plane shear strengthening of unreinforced masonry walls using GFRP jacketing. Period Polytech Civil Eng 62(2):330-336

36. Sagar SL, Singhal V, Rai DC, Gudur P (2017) Diagonal shear and out-of-plane flexural strength of fabric-reinforced cementitious matrix-strengthened masonry walletes. J Compos Constr 21(4):04017016

37. Carozzi FG, D'Antino T, Poggi C (2018) In-situ experimental tests on masonry panels strengthened with Textile Reinforced Mortar composites. Proc Struct Integr 11:355-362

38. Giaretton M, Dizhur D, Garbin E, Ingham JM, da Porto F (2018) In-plane strengthening of clay brick and block masonry walls using textile-reinforced mortar. J Compos Constr 22(5):04018028

39. Incerti A, Tilocca AR, Ferretti F, Mazzotti C (2019) Influence of masonry texture on the shear strength of FRCM reinforced panels.
In: Structural analysis of historical constructions. Springer, Cham, pp. $1623-1631$

40. Ismail N, El-Maaddawy T, Khattak N, Najmal A (2018) In-plane shear strength improvement of hollow concrete masonry panels using a fabric-reinforced cementitious matrix. J Compos Constr 22(2):04018004

41. Ismail N, El-Maaddawy T, Najmal A, Khattak N (2018) Experimental in-plane performance of insulated concrete and brick masonry wall panels retrofitted using polymer composites. Bull N Z Soc Earthq Eng 51(2):85-91

42. Shabdin M, Zargaran M, Attari NK (2018) Experimental diagonal tension (shear) test of Un-Reinforced Masonry (URM) walls strengthened with textile reinforced mortar (TRM). Constr Build Mater 164:704-715

43. Wang X, Lam CC, Iu VP (2018) Experimental investigation of inplane shear behaviour of grey clay brick masonry panels strengthened with SRG. Eng Struct 162:84-96

44. Casacci S, Gentilini C, Di Tommaso A, Oliveira DV (2019) Shear strengthening of masonry wallettes resorting to structural repointing and FRCM composites. Constr Build Mater 206:19-34

45. D'Antino T, Carozzi FG, Poggi C (2019) Diagonal compression of masonry walls strengthened with composite reinforced mortar. In: Key Engineering Materials, vol 817. Trans Tech Publications Ltd., pp 528-535

46. Del Zoppo M, Di Ludovico M, Balsamo A, Prota A (2019) Experimental in-plane shear capacity of clay brick masonry panels strengthened with FRCM and FRM composites. J Compos Constr 23(5):04019038

47. Ferretti F, Incerti A, Tilocca AR, Mazzotti C (2019) In-plane shear behavior of stone masonry panels strengthened through grout injection and fiber reinforced cementitious matrices. Int $\mathrm{J}$ Archit Herit. https://doi.org/10.1080/15583058.2019.1675803

48. Incerti A, Ferretti F, Mazzotti C (2019) FRCM strengthening systems efficiency on the shear behavior of pre-damaged masonry panels: an experimental study. J Build Pathol Rehabil 4(1):14

49. Tilocca AR, Incerti A, Bellini A, Savoia M (2019) Influence of matrix properties on FRCM-CRM strengthening systems. In: Key engineering materials, vol 817. Trans Tech Publications Ltd., pp 478-485

50. Wang X, Lam CC, Iu VP (2019) Comparison of different types of TRM composites for strengthening masonry panels. Constr Build Mater 219:184-194

51. Dalalbashi A, Ghiassi B, Oliveira DV (2020) In-plane behavior of clay brick masonry wallets strengthened with TRM system. In: 3D RILEM spring convention 2020 at Guimarães, Portugal

52. Mercedes L, Bernat-Maso E, Gil L (2020) In-plane cyclic loading of masonry walls strengthened by vegetal-fabric-reinforced cementitious matrix (FRCM) composites. Eng Struct 221:111097

53. Tripathy D, Meghwal P, Singhal V (2020) Strengthening of lime mortar masonry wallettes using fiber-reinforced cementitious matrix. J Compos Constr 24(6):04020075

54. Gulinelli P, Aprile A, Rizzoni R, Grunevald YH, Lebon F (2020) Multiscale numerical analysis of TRM-reinforced masonry under diagonal compression tests. Buildings 10(11):196

55. Torres B, Varona FB, Baeza FJ, Bru D, Ivorra S (2020) Study on retrofitted masonry elements under shear using digital image correlation. Sensors 20(7):2122

56. Donnini J, Maracchini G, Lenci S, Corinaldesi V, Quagliarini E (2021) TRM reinforced tuff and fired clay brick masonry: experimental and analytical investigation on their in-plane and out-ofplane behavior. Constr Build Mater 272:121643

57. Triantafillou TC, Karlos K, Kefalou K, Argyropoulou E (2017) An innovative structural and energy retrofitting system for URM walls using textile reinforced mortars combined with thermal insulation: mechanical and fire behavior. Constr Build Mater 133:1-13 
58. Bournas DA (2018) Concurrent seismic and energy retrofitting of $\mathrm{RC}$ and masonry building envelopes using inorganic textile-based composites combined with insulation materials: a new concept. Compos B Eng 148:166-179

59. Longo F, Lassandro P, Moshiri A, Phatak T, Aiello MA, Krakowiak KJ (2020) Lightweight geopolymer-based mortars for the structural and energy retrofit of buildings. Energy Build 225:110352

60. Longo F, Cascardi A, Lassandro P, Aiello MA (2020) A new Fabric Reinforced Geopolymer Mortar (FRGM) with mechanical and energy benefits. Fibers 8(8):49

61. Haq EU, Padmanabhan SK, Licciulli A (2014) In-situ carbonation of alkali activated fly ash geopolymer. Constr Build Mater 66:781-786

62. Provis JL, Van Deventer JSJ (eds) (2009) Geopolymers: structures, processing, properties and industrial applications. Elsevier, Amsterdam

63. Alanazi H, Hu J, Kim YR (2019) Effect of slag, silica fume, and metakaolin on properties and performance of alkali-activated fly ash cured at ambient temperature. Constr Build Mater 197:747-756

64. Aydin E (2017) Staple wire-reinforced high-volume fly-ash cement paste composites. Constr Build Mater 153:393-401

65. Atiyeh M, Aydin E (2020) Carbon-fiber enriched cement-based composites for better sustainability. Materials 13(8):1899

66. Al-Subari L, Ekinci A, Aydın E (2021) The utilization of waste rubber tire powder to improve the mechanical properties of cement-clay composites. Constr Build Mater 300:124306

67. Micelli F, Maddaloni G, Longo F, Prota A (2021) Axial stressstrain model for frem confinement of masonry columns. J Compos Constr 25(1):04020078

68. UNI E (2007) 771-1:2015. Specification for masonry units-Part 1: Clay masonry units

69. UNI E (2007) 1015-11. Methods of test for mortar for masonryPart 11: determination of flexural and compressive strength of hardened mortar

70. UNI E (2001) 1052-1. Methods of test for masonry-determination of compressive strength

71. Consiglio Superiore dei Lavori Pubblici CS (2015) Linea Guida per la identificazione, la qualificazione ed il controllo di accettazione di compositi fibrorinforzati a matrice inorganica (FRCM) da utilizzarsi per il consolidamento strutturale di costruzioni esistenti. In Italian. Standards for the Qualification of Fabric Reinforced Cementitious Mortar (FRCM) composites for the reinforcement of existing structures

72. ASTM C518-04 (2004) Standard test method for steady-state thermal transmission properties by means of the heat flow meter apparatus. ASTM International, West Conshohocken. www.astm. org

73. ASTM E1530-06 (2006) Standard test method for evaluating the resistance to thermal transmission of materials by the guarded heat flow meter technique. ASTM International, West Conshohocken. www.astm.org

74. Howell JR, Siegel R, Mengüç MP (1969) Thermal radiation heat transfer. National Aeronautics and Space Administration

75. Albatici R, Passerini F, Tonelli AM, Gialanella S (2013) Assessment of the thermal emissivity value of building materials using an infrared thermovision technique emissometer. Energy Build 66:33-40

76. Emmel MG, Abadie MO, Mendes N (2007) New external convective heat transfer coefficient correlations for isolated low-rise buildings. Energy Build 39(3):335-342

77. ASTM E519 / E519M-10 (2010) Standard test method for diagonal tension (shear) in masonry assemblages. ASTM International, West Conshohocken. www.astm.org

78. Donatelli A, Aversa P, Luprano VAM (2016) Set-up of an experimental procedure for the measurement of thermal transmittances via infrared thermography on lab-made prototype walls. Infrared Phys Technol 79:135-143

79. Kontoleon KJ, Theodosiou TG, Tsikaloudaki KG (2013) The influence of concrete density and conductivity on walls' thermal inertia parameters under a variety of masonry and insulation placements. Appl Energy 112:325-337

80. Park JK, Kim MO, Kim DJ (2020) Pullout behavior of recycled waste fishing net fibers embedded in cement mortar. Materials 13(18):4195

Publisher's Note Springer Nature remains neutral with regard to jurisdictional claims in published maps and institutional affiliations. 